\title{
Micronekton distribution in the southwest Pacific (New Caledonia) inferred from shipboard-ADCP backscatter data
}

\author{
Receveur Aurore ${ }^{1,{ }^{*}}$, Kestenare Elodie ${ }^{2}$, Allain Valerie ${ }^{1}$, Ménard Frédéric ${ }^{3}$, Cravatte Sophie ${ }^{2}$, \\ Lebourges-Dhaussy Anne ${ }^{4}$, Lehodey Patrick ${ }^{5}$, Mangeas Morgan ${ }^{6}$, Smith Neville ${ }^{1}$, \\ Radenac Marie-Hélène ${ }^{2}$, Menkes Christophe ${ }^{6}$
}

1 OFP/FEMA, Pacific Community, 95 Promenade Roger Laroque, BP D5, 98848 Nouméa, NouvelleCalédonie

2 LEGOS, Univ.de Toulouse, IRD, CNES, CNRS, UPS, 14 Avenue Edouard Belin, 31400 Toulouse, France

${ }^{3}$ Aix Marseille Univ., Univ. de Toulon, CNRS, IRD, MIO, Campus de Luminy - OCEANOMED, Bâtiment Méditerranée, 13288 Marseille, France

4 IRD, Univ. Brest, CNRS, Ifremer, LEMAR, Campus Ifremer, BP70, 29280 Plouzané, France

${ }^{5}$ CLS, Sustainable Fisheries, Marine Ecosystem Modelling, 11 Rue Hermes, 31520 Ramonville, France

${ }^{6}$ ENTROPIE, UMR 9220, IRD, Univ. de La Réunion, CNRS, 101 Promenade Roger Laroque, 98800

Nouméa, Nouvelle-Calédonie

* Corresponding author : Aurore Receveur, email address : aurorer@spc.int

\begin{abstract}
:
Acoustic data are invaluable information sources for characterizing the distribution and abundance of midtrophic-level organisms (micronekton). These organisms play a pivotal role in the ecosystem as prey of top predators and as predators of low-trophic-level organisms. Although shipboard-ADCP (acoustic Doppler current profiler) acoustic backscatter signal intensity cannot provide an absolute biomass estimate, it may be a useful proxy to investigate variability in the distribution and relative density of micronekton. This study used acoustic recordings data spread across 19 years (1999-2017) from 54 ADCP cruises in New Caledonia's subtropical EEZ (exclusive economic zone) to assess seasonal and interannual variabilities and spatial distribution of micronekton. The dataset was composed of two different ADCPs: $150 \mathrm{kHz}$ for the first period, followed by $75 \mathrm{kHz}$ for more recent years. We examined the 20-120 $\mathrm{m}$ averaged scattering layer. Using the few cruises with concurrent EK60 measurements, we proposed that the backscatter from the ADCPs and $70 \mathrm{kHz}$ EK60 were sufficiently closely linked to allow the use of the backscatter signal from the ADCPs in a combined dataset over the full time series. We then designed a GAMM (generalized additive mixed model) model that takes into account the two ADCP devices as well as temporal variability. After accounting for the effect of the devices, we showed that the acoustic signal was mainly driven by diel vertical migration, season, year, and ENSO (EI Niño-Southern Oscillation). In a second step, a consensus model between two statistical approaches (GAMM and SVM) (support vector machine) was constructed, linking the nighttime 20-120 m backscatter to the oceanographic and geographic environment. This model showed that sea surface temperature was the main factor driving backscatter variability in the EEZ, with intensified backscatter during the austral summer (December to May) in the northern part of the EEZ. We showed that acoustic density differed significantly, spatially and temporally from micronekton biomass predicted for the same period by the SEAPODYM-MTL (mid-trophic level) ecosystem model. The seasonal cycle given by ADCP data lagged behind the SEAPODYM-MTL
\end{abstract}


seasonal cycle by around three months. Reasons to explain these differences and further needs in observation and modeling were explored in the discussion. In addition to providing new insights for micronekton dynamics in this EEZ (i.e., the science needed for ecosystem-based fisheries management), the data should help improve our ability to model this key trophic component.

\section{Highlights}

20 years of ADCP acoustic data give insights on spatiotemporal micronekton dynamics. Sea-surface temperature is the main factor driving the backscatter variability. Backscatter values are enhanced during El Niño events in New Caledonia's EEZ. Micronekton spatial distribution changes across seasons according to backscatter. Spatial and temporal distribution of micronekton differ between SEAPODYM and ADCP'.

Keywords : Micronekton, southwest Pacific Ocean, SEAPODYM, acoustic, ecosystem 


\section{Introduction}

33 In the western Pacific, marine pelagic predators, particularly tuna, are a major food and

34 economic resource for small island developing states (Bell et al., 2015). Tuna distribution

35 variability in space and time has been linked to oceanographic factors (e.g., temperature,

36 depth and oxygen) or biological factors (e.g., age and reproduction) (Brill et al., 2005; Young

37 et al., 2011). However, the presence and availability of forage fauna remains a key driver of

38 tuna distribution (Bertrand et al., 2002; Duffy et al., 2017; Olson et al., 2014).

39 Tuna forage fauna is mostly composed of micronekton, which are mid-trophic-level

40 organisms comprising crustaceans, molluscs, gelatinous organisms, and fish measuring

41 between 1 and $20 \mathrm{~cm}$ (Bertrand et al., 2002; Young et al., 2015). Distributed in the upper

$421000 \mathrm{~m}$ of the water column (Gjøsaeter and Kawaguchi, 1980), micronekton are layer-

43 distributed (Burgos and Horne, 2008). Vertical layer positions are influenced by physical-

44 chemical properties of the water mass such as oxygen or temperature (Klevjer et al., 2016), or

45 by the presence of predators (Benoit-Bird et al., 2017). Micronekton abundance is also

46 influenced by environmental conditions such as primary production (Escobar-Flores et al.,

47 2013; Irigoien et al., 2014) or the presence of eddies or fronts (Behagle et al., 2016; Sabarros

48 et al., 2009). A large proportion of micronekton organisms undertakes diel vertical migrations

49 (DVM), moving from the mesopelagic zone (200-1000 m), where they stay during the day, to

50 the more productive surface layer $(0-200 \mathrm{~m})$ during the night (Pearre, 2003). DVM are

51 observed across all oceans (Bianchi and Mislan, 2016; Klevjer et al., 2016) and are

52 recognized today as the biggest biomass movement on earth (Hays, 2003). In addition to their

53 pivotal role between low trophic-level organisms and top predators (Bedford et al., 2015;

54 Giménez et al., 2018), micronekton actively contribute to the downward flux of nutrients and

55 particulate organic matter by their DVM (Ariza et al., 2016, 2015; Drazen and Sutton, 2017;

56 Kiko et al., 2017).

57 Understanding the dynamics of micronekton in the water column and their horizontal spatial

58 distribution at different scales remains challenging. Net trawling is the traditional sampling

59 approach (Potier et al., 2014). Trawl data, however, are size and/or species dependent due to

60 the net avoidance behavior of organisms; therefore, obtaining an unbiased quantitative

61 estimate with trawls is challenging (Heino et al., 2011; Kaartvedt et al., 2012). Further, trawls

62 are temporally and spatially discrete data, which complicates their use in attempting to have

63 large-scale micronekton estimates of the area considered. Therefore, net sampling is often 
64 complemented by the use of echosounders to study the distribution and behavior of pelagic

65 biota. Two types of echosounders exist: calibrated and un-calibrated. Calibrated

66 echosounders, initially devoted for studying the behavior of pelagic organisms, are widely

67 used to study the organism distribution throughout the water column (e.g., Cade and Benoit-

68 Bird, 2015; Kloser et al., 2002).

69 The sampling coverage from the shipboard un-calibrated acoustic Doppler current profiler (S70 ADCP, hereafter referred to "ADCP") is potentially huge compared with the one available 71 from calibrated echosounders. Indeed, given that the ADCP, initially devoted for measuring 72 current velocities, has been used routinely for several decades to measure currents, ADCP 73 records can provide much wider spatial and temporal coverage than scientific echosounders.

74 Moreover, ADCPs have been successfully compared with calibrated echosounders (Brierley 75 et al., 1998; Fiedler et al., 1998; Gostiaux and van Haren, 2010; Griffiths, 1996; Lee et al., 76 2004), suggesting that ADCPs can provide a proxy of relative density of combined 77 zooplankton and micronekton (Lee et al., 2004; Menkes et al., 2015; Radenac et al., 2010). 78 Several studies have used ADCP records to investigate the distribution and variability of 79 scattering layers in the ocean (e.g., Chereskin and Tarling, 2007; Radenac et al., 2010; Smeti 80 et al., 2015). These studies used the method developed by Flagg and Smith (1989), which allows the use of ADCP echo intensity as a proxy for abundance.

82 For both calibrated and un-calibrated echosounders, organism biomass estimation needs the knowledge of community species composition and their target strengths. To achieve a better discrimination between species or groups of species, a combination of methods such as net sampling (e.g., Nishikawa et al., 2001), optics measurements using videos (e.g., Kloser et al., 2016), eDNA (e.g., Bohmann et al., 2014), or recording several frequencies (e.g., Davison et al., 2015b) is recommended. Moreover, scattering of layers recorded by both types of echosounders could be dominated by some organisms' resonance that hides weaker scatterers and, therefore, the echo intensity recorded is less representative of all micronektonic species that are present.

91 Net sampling and acoustic data also provide critical information to calibrate and validate ecosystem models, including a representation of mid-trophic functional groups (Handegard et

93 al., 2013). Such models allow for estimating, at regional and global scales, the biomass of 94 micronekton based on key biological processes and first ecological principles such as growth 95 and mortality rates with temperature. SEAPODYM - Spatial Ecosystem and Population 4 
Dynamics Model - is a model where both micronekton groups and predator fish (e.g., tuna) population dynamics are described (Lehodey et al., 2010, 2008). A method has been developed to assimilate biomass observations in this model for the estimation of energy transfer efficiency coefficients between micronekton groups (e.g., migrant and resident). It has been demonstrated, using acoustic data directly, that acoustic signal and biomass are directly proportional (Lehodey et al., 2015). To explore the interest in using existing abundant and archived ADCP data in a future data assimilation ecosystem modeling framework, we investigate a 19-year time series of ADCP data, collected through 54 oceanographic cruises in New Caledonia's exclusive economic zone (EEZ).

105 New Caledonia is located in the Coral Sea at the southwestern edge of the Pacific Ocean. New Caledonia and the nearby Vanuatu Archipelago create an obstacle to the westward South Equatorial Current (SEC), the dominant feature of water circulation for surface, thermocline and intermediate waters. The SEC is divided into zonal jets when encountering New

109 Caledonia's islands, and finally, waters above the thermocline diverge into two branches 110 around $15^{\circ} \mathrm{S}$ when reaching the Australian coast (Cravatte et al., 2015). In this region, general 111 circulation models are prone to shear instabilities, and high eddy kinetic energy is observed 112 (Qiu et al., 2009; Rousselet et al., 2016), which may influence the distribution of deep-sea 113 organisms (Behagle et al., 2014; Tew Kai and Marsac, 2010). On the western barrier reef of 114 New Caledonia's main island, strong winds during the austral summer (December to May) 115 also create upwelling conditions that cool the sea's surface temperature and create the vertical 116 movement of nutrients (Alory et al., 2006; Ganachaud et al., 2010; Marchesiello et al., 2010). 117 Excluding very coastal areas, New Caledonia's EEZ is regarded as oligotrophic, with a higher 118 productivity zone south of $22^{\circ} \mathrm{S}$ (Ceccarelli et al., 2013; Dandonneau and Gohin, 1984).

119 The active management of the recently created Coral Sea Natural Park (Decree 2014$1201063 / \mathrm{GNC}$ ) creates a need for robust information on the productivity and functioning of this 121 remarkable ecosystem, including micronekton dynamics and the pivotal role of micronekton 122 in food webs. Micronekton taxonomy, distribution and biomass are still poorly known in the 123 Coral Sea (Ceccarelli et al., 2013) and in New Caledonia's EEZ (Gardes et al., 2014). Top 124 predator diet studies (Allain et al., 2012; Olson et al., 2014; Williams et al., 2014; Young et 125 al., 2010) and trawl data analyses (Grandperrin et al., 1999; Menkes et al., 2015; Young et al., 126 2011) have emphasized a high level of diversity in macro-zooplankton and micronekton, with 127 a dominance of Gonostomatidae, Sternoptychidae, Myctophidae, Scopelarchidae and 
128 Phosichthyidae (Ceccarelli et al., 2013; Grandperrin, 1975; Sutton et al., 2017; Vourey et al., 129 2017).

130 Behind these studies focusing on species diversity, the amount of data collected specifically to 131 study micronekton abundance, together with co-located oceanographic conditions, are still 132 rare (Menkes et al., 2015; Smeti et al., 2015). In New Caledonia's EEZ, poor data coverage 133 prohibits a comprehensive description of the pelagic ecosystem, including the main seasonal 134 patterns of micronekton and their relationship with oceanographic drivers. In the present 135 paper, we focused on analyzing the spatial and seasonal variability of acoustic backscatter 136 collected around New Caledonia, and its relationship with oceanographic conditions, 137 assuming that backscatter values are a proxy for the relative abundance of micronekton. First, 138 we proposed a simple approach of inter-calibration between various instruments. We 139 described DVM, seasonal cycles, and multi-year trends in backscatter data. Then, the effect of 140 environmental variables (e.g., bathymetry, distance to the closest coast, sea surface 141 temperature, chlorophyll- $a$, and thermocline depth) on backscatter values was investigated

142 through statistical models, providing backscatter predictions at the scale of the EEZ. Finally, 143 we compared acoustic data from the ADCP model to micronekton outputs of SEAPODYM 144 simulations. In the discussion, pathways were proposed to progress on the observation, 145 understanding and modeling of micronekton.

\section{Methods}

147 Micronekton dynamics are usually studied using calibrated echosounders such as SIMRAD 148 EK60 systems. However, in the New Caledonian region, EK60 systems have been 149 occasionally used to collect acoustic data (6 cruises) whereas un-calibrated ADCPs, usually 150 switched-on for current measurements onboard oceanographic vessels, have been routinely 151 used to collect data (54 cruises) between 1999 and 2017. Hence, despite the lack of 152 calibration, ADCP offers a longer time series and wider spatial coverage than calibrated 153 acoustic data for this region. 

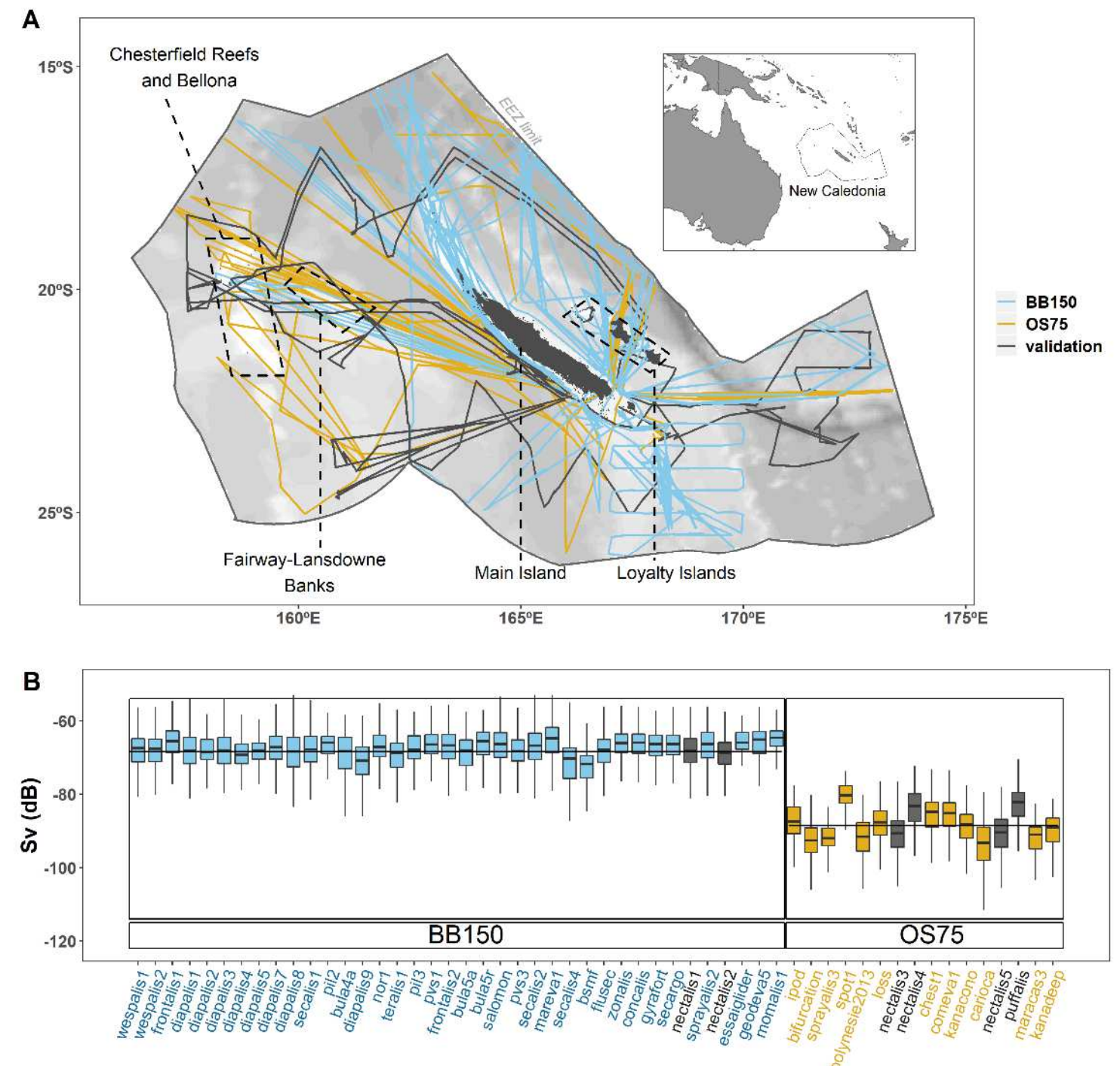

155 Figure 1: Map showing cruise tracks of the R/V Alis (solid lines) with S-ADCP device (blue line for $156150 \mathrm{kHz}$, yellow line for $75 \mathrm{kHz}$, and grey line for cruises used for ADCP validation) in New

157 Caledonia's exclusive economic zone. Background grey colors represent seabed depth (lighter colors 158 indicate shallower depths). Important areas discussed in the paper are indicated by grey dashed line 159 (panel A). Panel B shows boxplots of ADCP backscatter values per cruise with the same color code 160 used for the map.

\subsection{Acoustic data}

162 We gathered historical ADCP data from 54 cruises on board the R/V Alis in New Caledonia's 163 EEZ $\left(156^{\circ} \mathrm{E}-174^{\circ} \mathrm{E}\right.$ and $\left.14^{\circ} \mathrm{S}-27^{\circ} \mathrm{S}\right)$ from 1999 to 2017 (Fig. 1, Table 1 and Appendix A, Fig. 164 A1). 
165 Table 1: Number of 10-km transects per season, warm season: DJF (December, January, February)

166 and MAM (March, April, May); and cold season: JJA (June, July, August) and SON (September,

167 October, November) and per year. Numbers in italics are for the $75 \mathrm{kHz}$ ADCP, all other numbers are

168 for the $150 \mathrm{kHz}$ ADCP.

169

$\begin{array}{lcccc}\mathbf{1 9 9 9} & \text { DJF } & \text { MAM } & \text { JJA } & \text { SON } \\ \mathbf{2 0 0 0} & 0 & 0 & 0 & 139 \\ \mathbf{2 0 0 1} & 0 & 115 & 0 & 0 \\ \mathbf{2 0 0 2} & 52 & 139 & 0 & 52 \\ \mathbf{2 0 0 3} & 12 & 89 & 0 & 0 \\ \mathbf{2 0 0 4} & 197 & 0 & 350 & 466 \\ \mathbf{2 0 0 5} & 503 & 140 & 123 & 202 \\ \mathbf{2 0 0 6} & 38 & 67 & 0 & 0 \\ \mathbf{2 0 0 7} & 0 & 0 & 0 & 94 \\ \mathbf{2 0 0 8} & 0 & 124 & 201 & 0 \\ \mathbf{2 0 0 9} & 0 & 512 & 182 & 0 \\ \mathbf{2 0 1 0} & 0 & 0 & 0 & 0 \\ \mathbf{2 0 1 1} & 0 & 233 & 0 & 0 \\ \mathbf{2 0 1 2} & 304 & 0 & 340 & 166 \\ \mathbf{2 0 1 3} & 0 & 174 & 100+106 & 323 \\ \mathbf{2 0 1 4} & 56 & 1 & 63 & 153 \\ \mathbf{2 0 1 5} & 154 & 0 & 0 & 207 \\ \mathbf{2 0 1 6} & 0 & 0 & 0 & 322 \\ \mathbf{2 0 1 7} & 127 & 233 & 85 & 327 \\ & 0 & 186 & 101 & 304\end{array}$

170 Two profilers were used: a $150 \mathrm{kHz}$ broadband ADCP (BBADCP), from October 1999 to

171 May 2012, and an Ocean Surveyor $75 \mathrm{kHz}$ narrowband ADCP (NBADCP) from October

1722012 to August 2017.

173 All ADCP data were processed using the freely available CODAS software ${ }^{1}$, and by applying

174 the procedure described in Hummon and Firing (2003). The echo intensity in counts, recorded

175 by the ADCP was converted to the backscatter coefficient $\left(S_{\mathrm{v}}\right.$ in dB.re. $\left.\mathrm{m}^{2}\right)$ using the standard

176 equation of sonar given by (RDI, 1998) for a NB-ADCP. Deines (1999) transformed this

177 equation for a BB-ADCP, subsequently rearranged by Gostiaux and van Haren (2010)

178 (Appendix B). The $150 \mathrm{kHz}$ ADCP backscatter data also had to be corrected due to a

179 technical bias due to two technical interventions, where the mean level of backscatter values

180 changed abruptly twice. Cruises were grouped in order to have the constant mean $S_{v}$ across

181 groups (i.e., Group1: Wespalis1 to Mareva1; Group2: Secalis4 to Secargo; and Group3:

182 Nectalis1 to Momalis) (Appendix B, Fig. B1). The maximum depth reached between these

1 http://currents.soest.hawaii.edu 
183 cruise groups was statistically different according to a Wilcoxon test (p-value $<0.05$ for 184 Group1-Group2, Group1-Group3 and Group2-Group3), which showed that changes in backscatter values were due to a technical bias and not to environmental changes. We adjusted backscatter values on a similar mean level across groups by adding offsets (Appendix B, Fig. B1). The final vertical resolution (bin) was $8 \mathrm{~m}$ for the $150 \mathrm{kHz}$ ADCP and $16 \mathrm{~m}$ for the $75 \mathrm{kHz}$ ADCP, both starting at $16 \mathrm{~m}$ depth and ending at $300 \mathrm{~m}$ for the $150 \mathrm{kHz}$, and at $700 \mathrm{~m}$ for the $75 \mathrm{kHz}$, with a time resolution of $5 \mathrm{~min}$.

We selected only the surface layer (20-120 m) because of the limited vertical range of the 150 kHz ADCP: its initial vertical range was $300 \mathrm{~m}$, but the depth actually reached after several years was limited to $120 \mathrm{~m}$ due to a decrease in the power of the device. Analyses were done on a thicker layer (20-200 m) with fewer cruises. The conclusions were similar, so the 20 $120 \mathrm{~m}$ layer was kept and considered representative of the epipelagic zone $(0-200 \mathrm{~m}) . \mathrm{S}_{\mathrm{v}}$ data were transformed into a linear scattering measure $\left(s_{v}=10^{\frac{s_{v}}{10}}\right)$ to be depth-averaged over 20$120 \mathrm{~m}$. In order to remove phenomena happening at high spatiotemporal resolution (EscobarFlores et al., 2018), the linear scattering measure was also averaged along survey traces every $10 \mathrm{~km}$, which corresponds approximately to 10 initial points with a vessel speed of $7 \mathrm{kt}$ ( 13 $\left.\mathrm{km} \cdot \mathrm{h}^{-1}\right)$. Sensitivity analyses using linear backscatter averaged over different spatial resolutions (5, 10 and $20 \mathrm{~km}$ ) and median values instead of the mean led to identical relationships to environmental variables and spatial predictions (not shown). Then, the logarithmic value $\left(S_{v}=10 * \log 10\left(s_{v}\right)\right)$ was calculated and used for all following analyses $\left(\mathrm{S}_{\mathrm{v}_{-} \mathrm{ADCP}}\right.$, in dB.re. $\left.\mathrm{m}^{2}\right)$ (Appendix A, Fig. A2).

To analyze the complete time series (from 1999 to 2017), the two ADCP frequencies needed to be examined together in order to look for a potential long temporal trend. For that purpose, we offered a method to replace the two ADCP signals on a similar mean level by comparing them to EK60 data. Both instruments were used simultaneously during six cruises: Nectalis 1 through 5 and Puffalis (cruise numbers 33, 35, 45, 46, 51, 52 in Appendix A, Table A1). During these cruises, the EK60 calibration was performed according to the method used by Foote et al. (1987) at the beginning of each cruise. As for ADCP, the mean value of the EK60 $\mathrm{S}_{\mathrm{v}}$ of the $70 \mathrm{kHz}$ frequency was calculated in the $20-120 \mathrm{~m}$ layer, with a $10-\mathrm{km}$ resolution.

2 Two linear regressions were fitted between the $S_{\mathrm{V}_{-} A D C P}$ values (one regression for each device: $3150 \mathrm{kHz}$ and $75 \mathrm{kHz}$ ) and $\mathrm{S}_{\mathrm{V}_{-} \text {EK60 }}$ values $(70 \mathrm{kHz})$. By comparing the two ADCP frequencies 4 to the same EK60 frequency, we assumed that a part of each ADCP signal was correlated to 
215 the EK60 signal. Based on the assumption that backscatter collected at $70 \mathrm{kHz}$ in six different

216 cruises using calibrated EK60 echosounders could be compared, an "ADCP corrected value"

217 relative to the EK60 $70 \mathrm{kHz}$ value was calculated. For the rest of the text, the "corrected

218 backscatter" ( $\mathrm{S}_{\mathrm{V}_{-} A D C P}$ _corrected $)$ corresponded to the $\mathrm{S}_{\mathrm{V} \_\mathrm{ADCP}}$ corrected with one of the two linear

219 regressions with EK60 values. These two regressions were used to adjust the same mean

220 backscatter reference level to the values of the two ADCP frequencies (Fig. 2).

221 The comparison with EK60 data made it possible to combine the two groups of cruises carried

222 out with the two ADCPs. The adjustment from $S_{\mathrm{V}_{-} A D C P}$ to $S_{\mathrm{v}_{-} E K 60}$ was made globally for each

223 group, assuming that 38 cruises $(150 \mathrm{kHz})$ on the one hand and 16 others $(75 \mathrm{kHz})$ on the

224 other were comparable. Indeed, in a group, it is considered that variations in $S_{v}$ values

225 between cruises are due solely to biological and environmental effects and not to a "device

226 effect" such as technical dependence on temperature. The influence of ambient temperature

227 on the backscatter calculation (Appendix B, Equation B1) was tested and found to be

228 negligible (not shown). Many previous studies have used a similar approach (e.g., Ashjian et

229 al., 2002; Bianchi and Mislan, 2016; Blanc et al., 2008; Chereskin and Tarling, 2007; Kaneda

230 et al., 2002; Liljebladh and Thomasson, 2001; Radenac et al., 2010; Tarling et al., 2001).

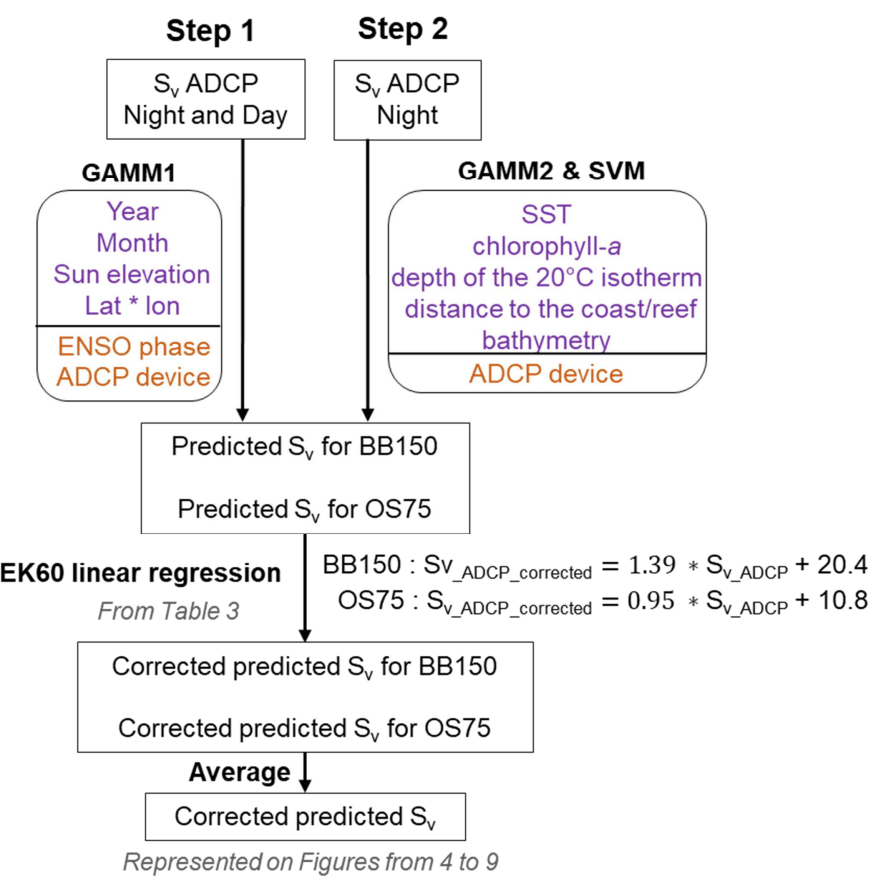

232 Figure 2: Diagram explaining the different steps of the analysis. For models GAMM1, GAMM2 and

233 SVM, purple variables are numerical and orange variables are qualitative.

234 


\subsection{Environmental data}

236 A suite of available environmental variables was selected to explore the physical drivers of

237 backscatter data. For each backscatter location, environmental variables were obtained at the

238 matching sampling position and date when data were available. Where real date data were not

239 available, climatologic data were used (Table 2).

240 Table 2: Environmental variable summary with unit, source, and resolutions detailed for each variable.

241 Variables with an asterisk (*) were downloaded via the Copernicus portal, CMEMS (Copernicus

242 Marine Environment Monitoring Service) (http://copernicus.eu/main/marine-monitoring). Variables

243 with (C) are climatologic.

\begin{tabular}{|c|c|c|c|c|}
\hline Variable name & Unit & Source & $\begin{array}{l}\text { Temporal } \\
\text { resolution }\end{array}$ & $\begin{array}{l}\text { Spatial } \\
\text { resolution }\end{array}$ \\
\hline Bathymetry & $\mathrm{km}$ & ZoNéCo, 2013 & - & $500 \mathrm{~m}$ \\
\hline $\begin{array}{l}\text { Distance to the closest } \\
\text { land or reef }\end{array}$ & $\mathrm{km}$ & from coastline and reef shapefiles & - & $1 / 4^{\circ}$ \\
\hline Sun elevation & $\circ$ & Calculated from position and date & - & - \\
\hline $\begin{array}{l}\text { 3D geostrophic zonal } \\
\text { and meridional currents } \\
\text { averaged on 30-100 m }\end{array}$ & $\mathrm{cm} / \mathrm{s}$ & $\begin{array}{c}\text { ARGO floats data and CSIRO } \\
\text { Atlas of the Regional Sea } \\
\text { (CARS2009) }\end{array}$ & $\begin{array}{l}\text { Annual } \\
\text { (C) }\end{array}$ & $1 / 4^{\circ}$ \\
\hline $\begin{array}{l}\text { SADCP zonal and } \\
\text { meridional currents in } \\
\text { the } 25-100 \text { m layer }\end{array}$ & $\mathrm{cm} / \mathrm{s}$ & Large ADCP dataset & $\begin{array}{l}\text { Quarter } \\
\text { (C) }\end{array}$ & $1 / 4^{\circ}$ \\
\hline $\begin{array}{l}\text { Surface zonal and } \\
\text { meridional seawater } \\
\text { velocity }(*)\end{array}$ & $\mathrm{m} / \mathrm{s}$ & MERCATOR GLORYS2V4 & Day & $1 / 4^{\circ}$ \\
\hline $\begin{array}{l}\text { Zonal and meridional } \\
\text { geostrophic currents in } \\
\text { the } 20-110 \text { m layer }(*)\end{array}$ & $\mathrm{m} / \mathrm{s}$ & ARMOR3D & Week & $1 / 4^{\circ}$ \\
\hline $\begin{array}{l}\text { Sea surface temperature } \\
(\mathrm{SST})(*)\end{array}$ & ${ }^{\circ} \mathrm{C}$ & $\begin{array}{c}\text { Advanced Very High Resolution } \\
\text { Radiometer (AVHRR) infrared } \\
\text { satellite }\end{array}$ & Day & $1 / 4^{\circ}$ \\
\hline Chlorophyll-a (*) & $\mathrm{mg} / \mathrm{m}^{3}$ & $\begin{array}{c}\text { GlobColour-Processors versions: } \\
\text { MODIS 2014.0.1/VIIRSN } \\
\text { 2014.0.2 }\end{array}$ & Day & $1 / 4^{\circ}$ \\
\hline $\begin{array}{l}\text { Sea level anomaly } \\
\quad(\text { SLA })(*)\end{array}$ & $\mathrm{m}$ & $\begin{array}{l}\text { DT all-sat-merged Global Ocean } \\
\text { Gridded SSALTO/DUACS Sea } \\
\text { Surface Height L4 product }\end{array}$ & Day & $1 / 4^{\circ}$ \\
\hline $\begin{array}{l}\text { Zonal and meridional } \\
\text { winds }(*)\end{array}$ & $\mathrm{m} / \mathrm{s}$ & $\begin{array}{l}\text { Cross-Calibrated Multi-Platform } \\
\text { (CCMP-v2) }\end{array}$ & Week & $1 / 4^{\circ}$ \\
\hline $\begin{array}{l}\text { Depth of the 20-degree } \\
\text { isotherm (D20) }(*)\end{array}$ & $\mathrm{m}$ & ARMOR3D & Week & $1 / 4^{\circ}$ \\
\hline
\end{tabular}


245 The bathymetry was extracted from a 500-m-resolution dataset (ZoNéCo, 2013), and the

246 Euclidean distance to the closest coastline or shallow reef $(0-30 \mathrm{~m})$ was calculated from a

247 coastline-reef shapefile (Andréfouët et al., 2008). Sun elevation was calculated for all points

248 with an adapted version (Blanc and Wald, 2012) of the formula given by Michalsky (1988), a

249 function of spatial position and date. Sun elevation negative values are for night (from $-90^{\circ}$ to

$2500^{\circ}$ ) and positive values for day (from $0^{\circ}$ to $90^{\circ}$ ).

251 Several products were tested for zonal and meridional currents: a mean absolute geostrophic

252 current climatology, based on 1000-m Argo floats combined with geostrophic currents

253 computed from the CSIRO Atlas of the Regional Sea (CARS 2009) (Kessler and Cravatte,

254 2013), seasonal ADCP current climatology (Cravatte et al., 2015), ARMOR3D gridded

255 weekly velocities derived from satellite and in situ observations (Guinehut et al., 2012, 2004;

256 Mulet et al., 2012), and the MERCATOR-OCEAN GLORYS ocean reanalysis. Other

257 oceanographic physical parameters used were sea level anomaly (Pujol et al., 2016), sea

258 surface temperature (Reynolds et al., 2007), and depth of the $20^{\circ} \mathrm{C}$ isotherm calculated from

259 the ARMOR3D dataset. We used surface vector winds from the Cross-Calibrated Multi-

260 Platform (CCMP-v2), produced using satellite, moored buoy, and model (Wentz et al., 2015).

261 One biological parameter was extracted from the GlobColour project: surface chlorophyll- $a$

262 (Saulquin et al., 2009). These geographic parameters and environmental datasets are detailed

263 in Table 2 and spatial patterns by quarter are presented in Appendix C.

264 To assess the ENSO effect, the Oceanic Niño Index (ONI) - a three-month running mean of 265 ERSST.v5 sea surface temperature (SST anomalies) in the El Niño 3.4 region $\left(5^{\circ} \mathrm{N}-5^{\circ} \mathrm{S}\right.$, $266120^{\circ}-170^{\circ} \mathrm{W}$ ) was used ${ }^{2}$. ENSO phases were defined with a 0.7 threshold; such that months 267 with an ONI above 0.7 were classified as El Niño, and months with an ONI below -0.7 as La 268 Niña.

\section{$269 \quad 2.3$ Statistical model and analysis}

270 GAM (generalized additive model) (Hastie and Tibshirani, 1995) and SVM (support vector 271 machine) (Cortes and Vapnik, 1995) statistical models were used to investigate the variability 272 of backscatter echo-intensities in New Caledonia's EEZ. We studied the temporal variability 273 (daily, monthly, multi-annually) as a first step, and the relationships between backscatter 
274 values and environmental variables as a second step to avoid collinearity problems (e.g.,

275 between SST and month) (Fig. 2). Each model used has specific advantages. GAM allows

276 variables to be ranked by relevance, and highlights the relationships between the response

277 variables and predictors (explanatory variables), which is interesting from an ecological point

278 of view. However, GAM is difficult to tune while respecting strong assumptions (e.g.,

279 absence of autocorrelation in residuals, error distributed normally). SVM, as the state-of-the-

280 art algorithm, has been applied in various scientific domains, especially in ecological niche

281 modeling (Drake et al., 2006; Palialexis et al., 2011). For this method there is no requirement

282 concerning predictors' distributions or autocorrelation (Hegel et al., 2010). Yet, it remains

283 difficult to interpret SVM results, and there is no straightforward method for explaining the

284 results and ranking the predictors by relevance. To interpret ecological phenomena, partial

285 dependence plots were produced by environmental variables to visually explore the marginal

286 effect of a given variable on the backscatter value, while other variables are fixed to their

287 mean values (Friedman, 2001). SVM partial dependence plots are not presented, as strong

288 interactions exist between predictors (Goldstein et al., 2015). Subsequent models were fitted

289 with both GAMM and SVM models, excluding each of the remaining terms, one at a time, to

290 assess the percentage of variation explained by predictor. We classified predictors according

291 to their importance in the model.

292 To account for autocorrelation between consecutive backscatter values, we used a GAMM.

293 We nested an autocorrelation structure of order 1 (i.e., a 10-km autocorrelation structure,

294 Ménard and Marchal, 2003), with a random effect fitted by cruises dealing with the

295 correlation structure (Dormann et al., 2007; Wood, 2006). The absence of collinearity was

296 checked in residuals. We used a Gaussian family with an identity link function, and adopted

297 restricted maximum likelihood as the smoothness selection criteria (Wood, 2011). All splines

298 were fitted with a maximum knot number of 10 to keep a relatively simple relationship. SVM

299 uses a functional relationship to map data onto a new hyperspace in which complex patterns

300 can be more simply represented (Drake et al., 2006; Muller et al., 2001). SVM parameters

301 were tuned (Gaussian kernel, gamma $=0.1$ and cost $=10$ ) by cross validation (Browne and

302 Cudeck, 1989). We calculated the root mean square error on the evaluation dataset by

303 removing data from each of the 54 cruises one by one.

304 To account for the potential difference between the two ADCP devices, we included an

305 ADCP device effect in all models (GAMM and SVM); therefore, backscatter values were 
predicted for each ADCP device, BB150 and OS75, respectively. We then corrected the predicted $S_{v}$ using the corresponding EK60 linear regressions, and finally averaged the corrected predicted values from the two devices (Fig. 2). The effect of the ADCP device included in each model is different. For the GAMM, it is a "fixed effect", meaning that relationships between backscatter and covariates have the same shape but with an offset function of the ADCP device. For the SVM approach, relationships linked to ADCP devices could have different shapes.

313 We explored visually the temporal dynamic over the entire time series (1999-2017) with 314 GAMM outputs. In a first step, GAMM1 allowed us to investigate relationships between $315 \mathrm{~S}_{\mathrm{V}_{-} \mathrm{ADCP}}$ values and a set of temporal and spatial predictors. Six predictors were tested: the 316 ADCP effect (BB150 or OS75) and the ENSO phase (Neutral, El Niño or La Niña) as categorical variables and sun elevation (a proxy for the moment of the day), year, month, latitude and longitude, as continuous variables (Fig. 2, step 1). The year variable was smoothed with a cubic spline, and the month variable with a cyclic cubic spline. Latitude and longitude were fitted inside the same isotropic spline (Wood et al., 2012) with a Gaussian process model smoothing basis (Golding and Purse, 2016; Miller et al., 2013). This spatial term was added to fit the mean spatial distribution pattern to account for differences in survey spatial localization across the years (Appendix A, Fig. A1).

In a second step, environmental variables described in Table 2 (i.e., bathymetry, distance to the coast or reef, sun elevation, currents (four different sources), SST, chlorophyll- $a$, sea level anomaly, winds and $20^{\circ} \mathrm{C}$ isotherm depth, and a fix effect of the ADCP device were included in GAMM2 and SVM (Fig. 2, step 2), independently of month or year variables. All variables were smoothed with cubic splines. Predictions were done on climatological environmental variables with a $1 / 4^{\circ}$-resolution grid and then averaged between models leading to a hybrid GAMM2-SVM prediction. A measure of the coherence between the two models was estimated through the coefficient of variation (i.e., standard deviation divided by mean), which ranged from 0 to $7 \%$. We applied two different standard deviation thresholds $(6 \%$, $2 \%$ ): the lower the coefficient of variation threshold, the higher the confidence in the prediction, but the lower the number of cells predicted. We used two statistical models to compare large spatial predictions, combine common patterns (Oppel et al., 2012), and ensure that conclusions are robust to the underlying statistical assumptions. Before constructing models, we confirmed that collinearity was not apparent among the predictors using variance 
338 inflation factors (VIFs) (O'Brien, 2007) and Spearman correlations between each pair of covariates. We considered covariates to be non-collinear when both Spearman correlations were inferior to 0.5 and VIFs were inferior to 3.0.

341 GAMM1 assesses the seasonal cycle by fitting a month variable as a continuous variable.

342 GAMM2-SVM does not include a month variable but uses relationships with environmental 343 variables (such as SST) in which seasonality is inherent to predict backscatter values at each 344 point; finally, the seasonal cycle is assessed by averaging all EEZ-predicted values by month.

345 All statistical analyses were performed with R (version 3.5.0, R Core Team 2016). GAMMs 346 were fitted using the gamm function of the R package $\operatorname{mgcv}$ (Wood, 2017). SVM was fitted 347 using the svm function of the R e1071 package (Meyer et al., 2017).

\subsection{SEAPODYM simulation}

349 The submodel of SEAPODYM for mid-trophic levels (MTL) simulates several functional 350 groups of micronekton for the oceanic epi- and mesopelagic layers (Lehodey et al., 2010, 2015). The spatial and temporal dynamics of production and biomass are modeled with a system of advection-diffusion-reaction equations driven by ocean temperature, horizontal currents, primary production, and euphotic depth. Currently, there are six groups of micronekton defined according to the DVM patterns of mesopelagic organisms between three broad epipelagic, upper and lower mesopelagic vertical layers. The euphotic depth $\mathrm{Z}_{\mathrm{eu}}$ is used to define the depth boundaries of the vertical layers (i.e., $0-1.5 * Z_{\mathrm{eu}}$ for the epipelagic layer, $1.5-4.5^{*} \mathrm{Z}_{\mathrm{eu}}$ for the mesopelagic layer, and $4.5-10.5^{*} \mathrm{Z}_{\mathrm{eu}}$ for the bathypelagic layer). In New Caledonia, $\mathrm{Z}_{\mathrm{eu}}$ is around $70-75 \mathrm{~m}$, hence the epipelagic layer in the model occupies the top $\sim 110 \mathrm{~m}$. During the day, only the epipelagic group inhabits the epipelagic layer, but during the night, it also includes the migrant upper-mesopelagic and highly migrant lower mesopelagic groups.

362 We compared the predicted backscatter to SEAPODYM-MTL-modeled micronekton 363 biomass, and used a SEAPODYM-MTL micronekton simulation for the 1999-2017 period. 364 The biomass of micronekton groups inhabiting the epipelagic layer at night was extracted at 365 the date and place of the ADCP data. Values were centered (the mean was subtracted) and 366 scaled (divided by the standard deviation) for both SEAPODYM and acoustic models. 
367 Biomass values were compared along the tracks by calculating correlations, and distribution

368 patterns compared over the whole of the EEZ.

\section{Results}

370 In total, $89,530 \mathrm{~km}$ of survey track across 435 days (288 days for the $150 \mathrm{kHz}$ ADCP and 147

371 for the $75 \mathrm{kHz}$ ADCP) over 19 years were analyzed in this study. All quarters were sampled

372 at least nine times during the study period (Table 1), and the whole EEZ was surveyed at least

373 once except for a small area in the southeast corner of the EEZ, and an area in the southwest

374 below the Chesterfield Reefs (Fig. 1).

\section{3.1 Comparison to EK60 values}

376 We compared the un-calibrated ADCP acoustic data to the calibrated EK60 echosounder data.

377 Two cruises were available with concomitant $150 \mathrm{kHz} \mathrm{S}_{\mathrm{V}_{-} \text {ADCP }}$ and $\mathrm{S}_{\mathrm{V}_{\_} \text {EK60 }}$ records (1110

378 paired values) and four cruises with $75 \mathrm{kHz} \mathrm{S}_{\mathrm{V}_{-} A D C P}$ and $\mathrm{S}_{\mathrm{V}_{-} \text {EK60 }}$ (1955 paired values). For both

379 ADCP frequencies, correlations between mean 20-120m $\mathrm{S}_{\mathrm{v} \_ \text {ADCP }}$ and $\mathrm{S}_{\mathrm{V} \_ \text {EK60 }}$ were significant 380 and higher than 0.8 (Fig. 3). The two regressions were significant (p-values <0.01) and had 381 different slopes: 1.05 (standard error 0.017) for the $75 \mathrm{kHz}$ ADCP, and 0.72 (standard error 382 0.012) for the $150 \mathrm{kHz}$ ADCP (Table 3). For the $75 \mathrm{kHz}$ ADCP, the data scatterplot from 383 Nectalis 4 and Puffalis on one side, and from Nectalis 3 and Nectalis 5 on the other side, 384 could warrant the estimation of different intercepts (Fig. 3).

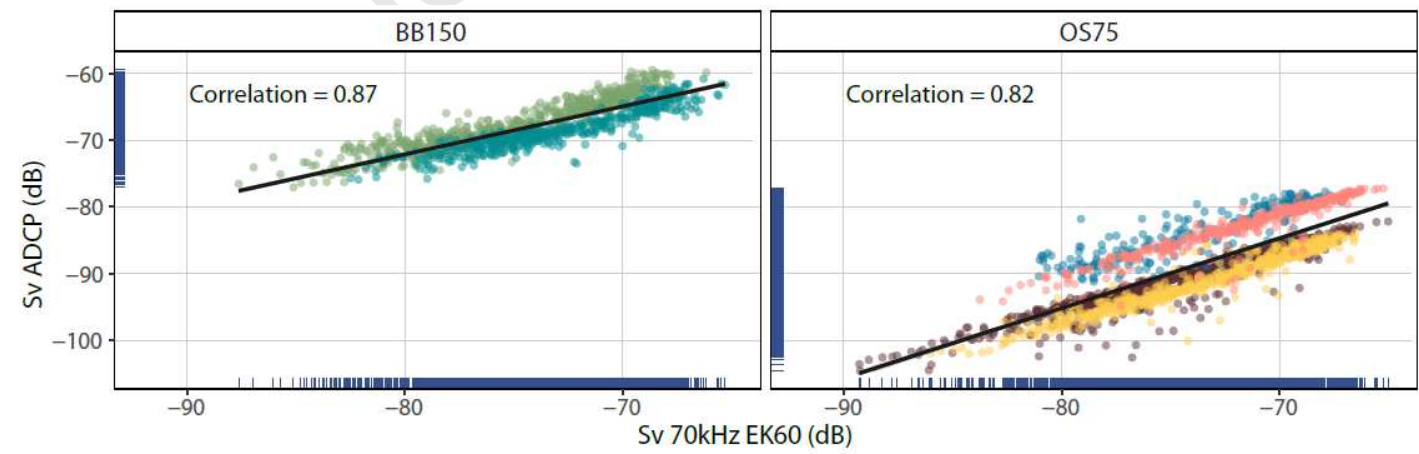

Cruises

nectalis1

nectalis2

औ nectalis3

nectalis4

nectalis5

puffalis

386 Figure 3: ADCP backscatter $\left(S_{\mathrm{v}}\right)$ as a function of the $70 \mathrm{kHz}$ EK60 echosounder $\mathrm{S}_{\mathrm{v}}$ and the associated 387 linear regressions (black line) for the $150 \mathrm{kHz}$ SADCP device (BB150, Nectalis 1 and 2) (left) and the $75 \mathrm{kHz}$ SADCP (OS75, Nectalis 3, 4, 5 and Puffalis) (right). Blue ticks on both axes show the distribution of the observations. 
392 Table 3 Linear regression analysis outputs, including the intercept, slope, slope standard error, p-value,

393 and deviation explained (or $\mathrm{R}^{2}$ ), and the number of observations for each ADCP device.

\begin{tabular}{|ccccccc|}
\hline ADCP device & Intercept & Slope & Slope standard error & Slope p-value & $\begin{array}{c}\text { Devation } \\
\text { explained }\end{array}$ & $\mathbf{n}$ \\
\hline OS75 & -11.32 & 1.05 & 0.017 & $<2 \mathrm{e}-16$ & 67 & 1955 \\
\hline BB150 & -14.64 & 0.72 & 0.012 & $<2 \mathrm{e}-16$ & 76 & 1110 \\
\hline
\end{tabular}

394

\subsection{Temporal variability of backscatter}

Temporal variability of backscatter micronekton was analyzed at three scales: daily, monthly and yearly using a GAMM, including all $S_{\mathrm{v} \_A D C P}$ values (night and day) as a function of ADCP device, sun elevation, year, ENSO phase, month and location (latitude and longitude) with a nested auto-correlative model (Fig. 2, left part). In this model, the largest part of the variance was explained by sun elevation (Table 4). $\mathrm{S}_{\mathrm{v} \_ \text {ADCP }}$ in the 20-120m layer was higher during the night than during the day (respectively, $-69 \mathrm{~dB}$ and $-75 \mathrm{~dB}$ ) (Fig. 4), a difference of $6 \mathrm{~dB}$. The usual value used as a density proxy is the linear value $\left(\mathrm{s}_{\mathrm{v}}\right)$, so a $6 \mathrm{~dB}$ difference meant that the micronekton density was about four times higher during the night than during the day in the $20-120 \mathrm{~m}$ layer. $S_{\mathrm{v}-A D C P}$ values were constant during the night, but started to decrease at dawn when sun elevation exceeded $-20^{\circ}$. The variance explained by sun elevation demonstrated the important impact of the DVM in the $20-120 \mathrm{~m}$ layer. The second most important variable was the effect of the ADCP device (Table 4). 


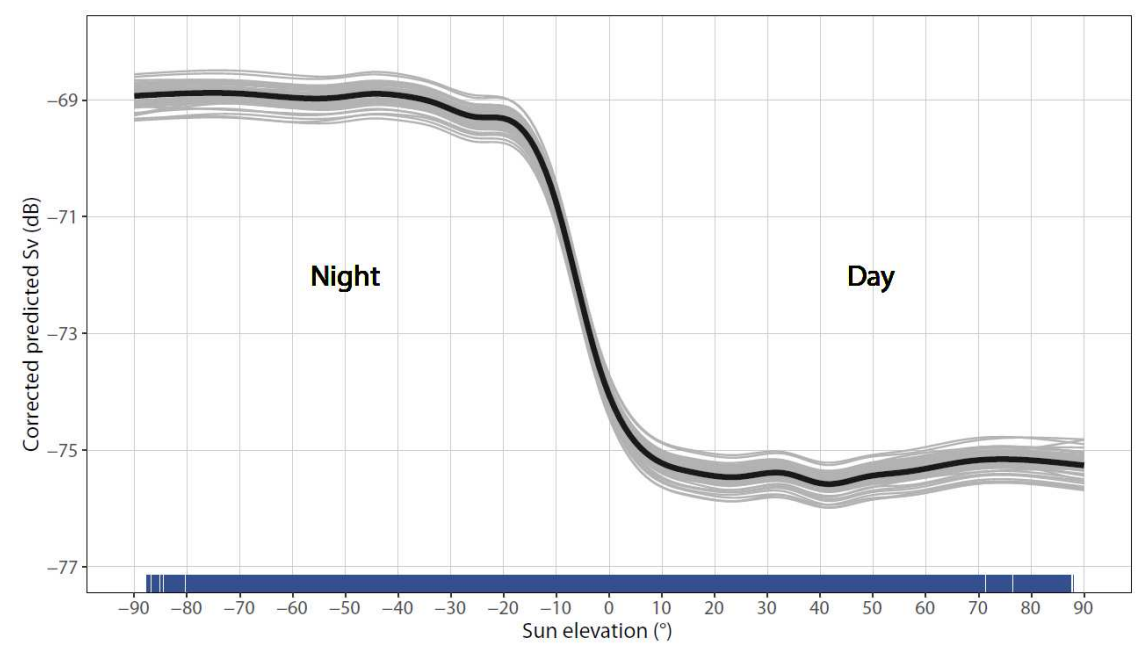

410 Figure 4: GAMM1 partial dependence plot showing the effect of sun elevation on corrected 411 backscatter values $\left(\mathrm{S}_{\mathrm{v}}\right)$. Solid grey lines are estimates of the smooths for the 54 simulations from 412 cross-validation, and the black line is the average smooth. Blue ticks on the inner X-axis show the 413 distribution of the observations .

414 Table 4: Model summary with the model name, response variable, explicative variables, total 415 deviation explained (or $\mathrm{R}^{2}$ ), and the rank of importance by variable. All predictors were significant in 416 the GAMMs output ( $\mathrm{p}$-values < 0.05). An asterisk $\left(^{*}\right)$ indicates that an auto-correlative model is 417 nested into the GAMM.

\begin{tabular}{|c|c|c|c|c|}
\hline Model & $\begin{array}{l}\text { Response } \\
\text { variable }\end{array}$ & $\begin{array}{c}\text { Explicative } \\
\text { variables }\end{array}$ & $\begin{array}{l}\text { Deviation } \\
\text { explained }\end{array}$ & $\begin{array}{c}\text { Rank of } \\
\text { importance by } \\
\text { variable }\end{array}$ \\
\hline \multirow{6}{*}{$\begin{array}{c}\text { GAMM1 } \\
(*)\end{array}$} & \multirow{6}{*}{$\mathrm{Sv}_{-A D C P}$} & Sun elevation & \multirow{6}{*}{83.9} & 1 \\
\hline & & year & & 5 \\
\hline & & month & & 3 \\
\hline & & Lat $*$ lon & & 4 \\
\hline & & ENSO_phase & & 6 \\
\hline & & ADCP_device & & 2 \\
\hline \multirow{6}{*}{$\begin{array}{c}\text { GAMM2 } \\
(*)\end{array}$} & \multirow{6}{*}{ Sv_ADCP_NIGHT } & SST & \multirow{6}{*}{78.1} & 2 \\
\hline & & $\mathrm{D} 20$ & & 4 \\
\hline & & Log_chloro & & 3 \\
\hline & & Bathy & & 5 \\
\hline & & Dist_coast & & 6 \\
\hline & & ADCP_device & & 1 \\
\hline \multirow{6}{*}{ SVM } & \multirow{6}{*}{$\mathrm{Sv}$ ADCP_NIGHT } & SST & \multirow{6}{*}{87.9} & 2 \\
\hline & & D20 & & 3 \\
\hline & & Log_chloro & & 6 \\
\hline & & Bathy & & 4 \\
\hline & & Dist_coast & & 5 \\
\hline & & ADCP_device & & 1 \\
\hline
\end{tabular}


419 Month was the third variable explaining the variance of $\mathrm{S}_{\mathrm{v} \_ \text {ADCP }}$ (Table 4). The seasonal cycle 420 displayed a maximum in March (-70.8 dB), and a minimum in September (-74.3 dB), with 421 two superimposed relative maxima in July and November $(-71.8 \mathrm{~dB}$ and $-72.8 \mathrm{~dB}$, 422 respectively) (Fig. 5). The difference between extreme values was about $3.5 \mathrm{~dB}$, meaning 423 there was, on average, 2.0 times more biomass during March than during September, 1.6 more 424 in July, and 1.4 more in November compared to September. The 54 cross-validation 425 simulations (Fig. 5) confirmed the robustness of the seasonal cycle.

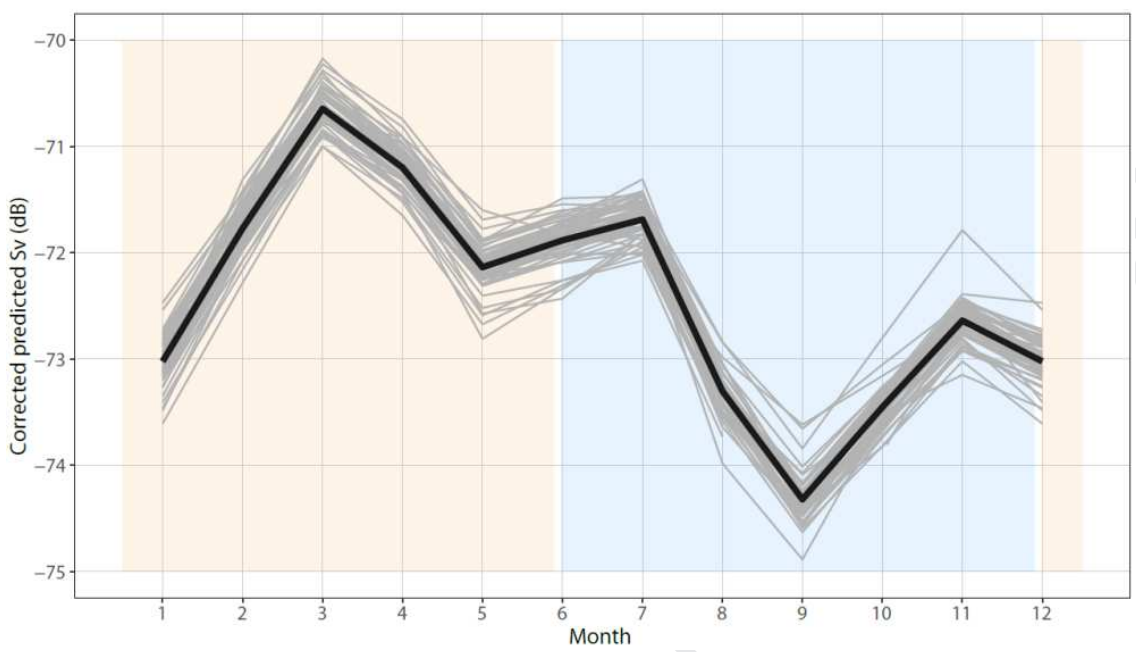

427 Figure 5: GAMM1 partial dependence plot showing the effect of the month on corrected backscatter 428 values $\left(\mathrm{S}_{\mathrm{v}}\right)$. Solid grey lines are estimates of the smooths for the 54 simulations from cross validation, 429 and the black line is the average smooth. Cold season is indicated in blue, and warm season in orange .

430 The variance explained placed the year variable at the $5^{\text {th }}$ rank and ENSO at the $6^{\text {th }}$ rank 431 (Table 4). The relationship between the $S_{\mathrm{v} \_A D C P}$ and the year was non-linear, with a minimum 432 and a maximum (Fig. 6A). Predicted $S_{\mathrm{V} \_ \text {ADCP }}$ were about $-73 \mathrm{~dB}$ in 1999 , decreasing to a 433 minimum of $-75 \mathrm{~dB}$ in 2007 , and reaching a maximum of $-71.5 \mathrm{~dB}$ in 2017. So, on average, 434 the acoustic density decreased by $1.6 \%$ between 1999 and 20017 and then increased by $2.2 \%$ 435 between 2007 and 2017. The ENSO phase effect was significant in the GAMM1: $\mathrm{S}_{\mathrm{v} \_ \text {ADCP }}$ was 436 twice as high during an El Niño phase than during a neutral phase (Fig. 6B), and the $\mathrm{S}_{\mathrm{v} \_ \text {ADCP }}$ during a La Niña phase was not significantly different from the value during a neutral phase. 

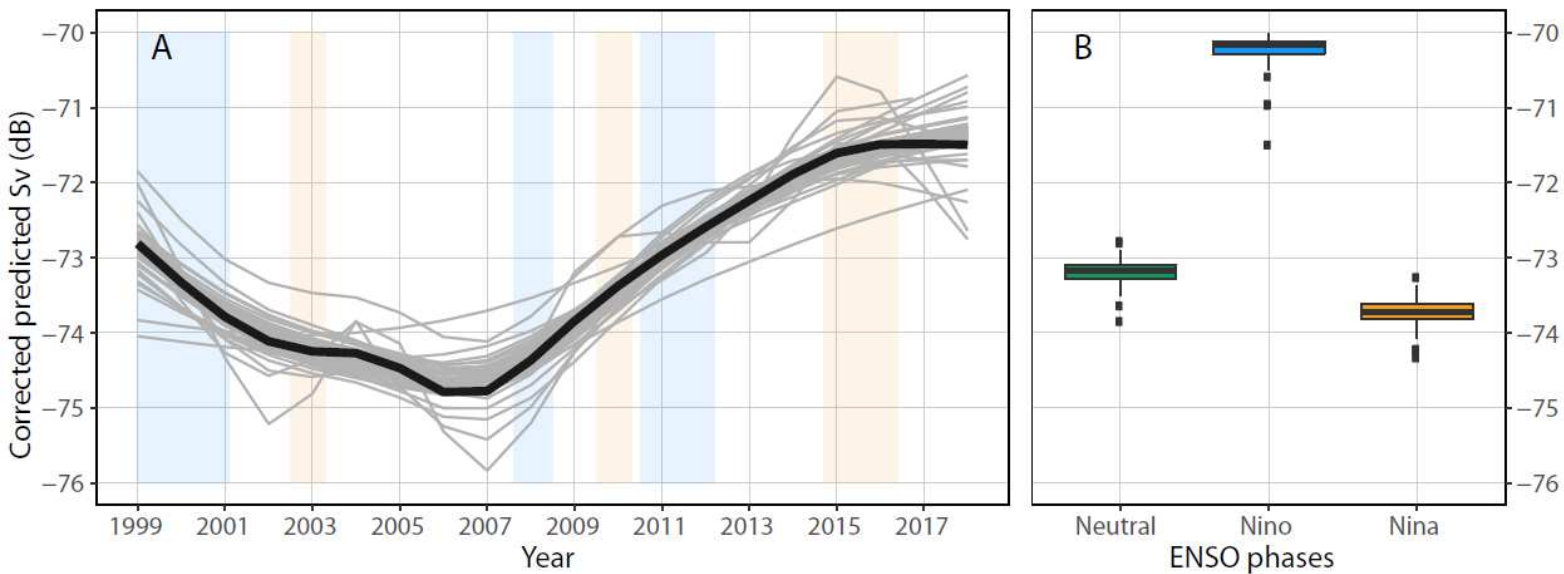

439 Figure 6: GAMM1 partial dependent plot terms showing the effect of year (A) and ENSO phases (B)

440 variables on corrected backscatter values $\left(S_{v}\right)$. Solid grey lines are estimates of the smooths for the 54

441 simulations from cross validation, and the black line is the average smooth. El Niño events are

442 indicated in blue on panel A, and in orange for La Niña events.

\section{$443 \quad 3.3$ Estimating ecological relationships}

444 To investigate the impact of environmental variables on $S_{\mathrm{V}_{-} \mathrm{ADCP}}$ values during the night, only

$445 \mathrm{~S}_{\mathrm{V}_{-} \text {ADCP_night }}$ were fitted through both a GAMM2 (with a nested auto-correlative model) and an 446 SVM with environmental variables and an effect on ADCP device (150 kHz or $75 \mathrm{kHz})$ (Fig.

447 2, right part). We focused this part of the study on nighttime values to reveal the potential 448 influence of environmental parameters that could have been masked by the strong impact of 449 sun elevation on backscatter. The night signal was preferred over the day signal because in the 450 20-120 $\mathrm{m}$ layer it better represents the micronekton community by accumulating both 451 permanent epipelagic organisms and migrating organisms coming from deeper layers.

452 Based on Spearman correlation tests and VIF, depth of the $20^{\circ} \mathrm{C}$ isotherm $(\mathrm{d} 20)$ and SLA 453 were correlated, which required selecting only one of those variables to be included in the 454 model. As SLA was not significant for the GAMM2 model, we kept d20 in the final model. 455 The zonal and meridional currents and wind data were un-significant in the GAMM2 model; 456 thus they were not considered further in models GAMM2 and SVM. The final models 457 included SST, chlorophyll- $a$, depth of the $20^{\circ} \mathrm{C}$ isotherm, distance to the coast or reef, 458 bathymetry, and the effect of the ADCP device for both the SVM and GAMM2 models.

459 After considering the effect of the ADCP device, the two statistical methods mostly agreed on 460 the relative contribution of variables (Table 4), with SST demonstrating the main effect 
among oceanographic variables. The contribution rank of chlorophyll- $a$ was different between the GAMM2 and SVM models: chlorophyll- $a$ was the second most important variable for GAMM2, and the last $\left(6^{\text {th }}\right)$ for SVM. Then, in descending order of importance, the $20^{\circ} \mathrm{C}$ isotherm depth, the bathymetry and the distance to the closest coast or reef were found to be important.
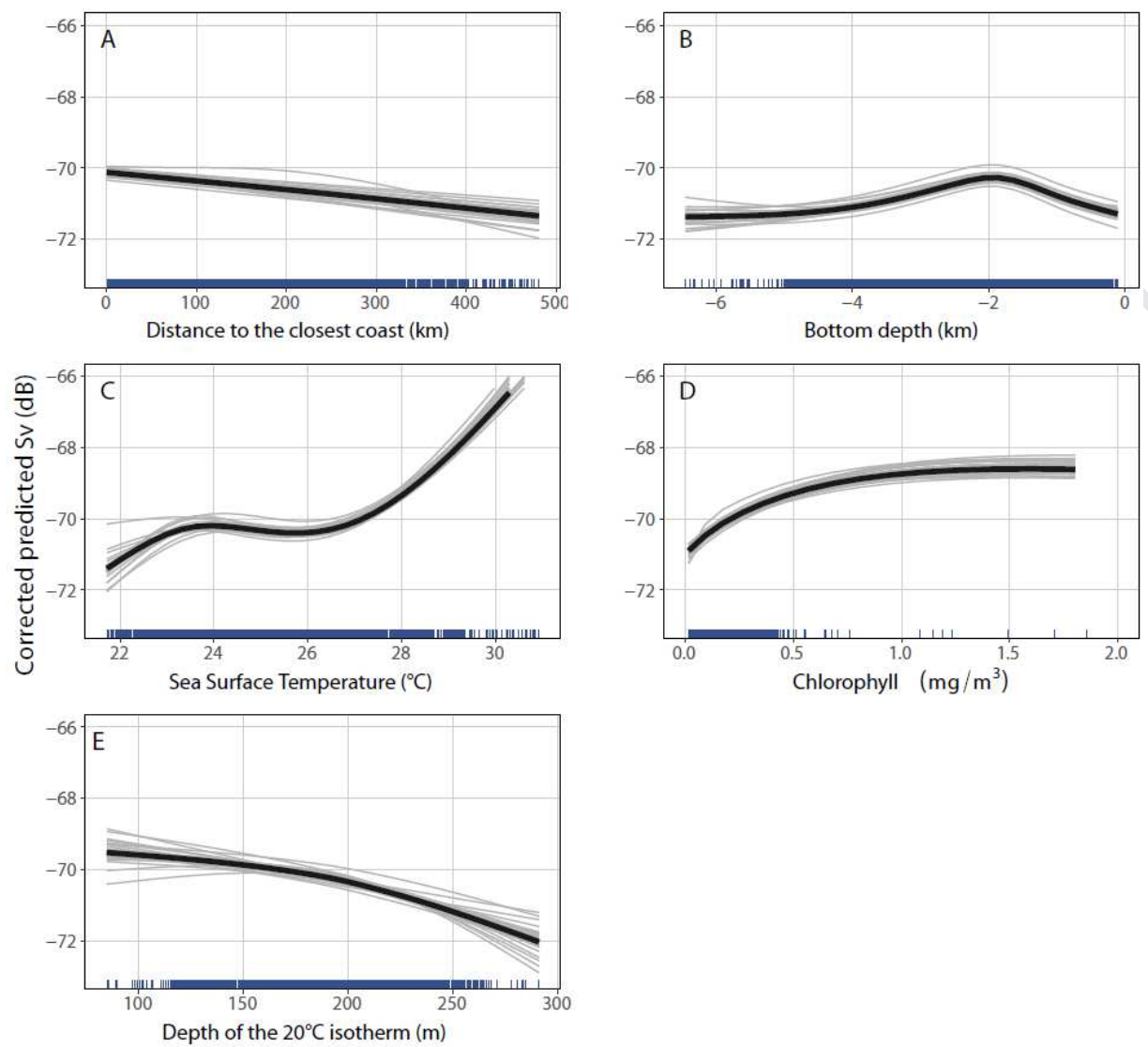

467 Figure 7: GAMM2 partial dependent plot terms showing the effect of various continuous variables on corrected backscatter values $\left(\mathrm{S}_{\mathrm{v}}\right)$. Solid grey lines are estimates of the smooths for the 54 crossvalidation simulations, and the black line is the average smooth. Blue ticks on the $\mathrm{X}$-axis show the distribution of observations .

471 The relationship between backscatter values and distance to the closest reef or coast linearly

472 decreased, with higher values closer to the coast (Fig. 7A). The influence of bathymetry was 473 not linear, but an optimum of the 20-120 m backscatter value was observed over the sea floor 474 at a depth of $1800 \mathrm{~m}$ (Fig. 7B). The SST relationship increased non-linearly, with a first 475 optimum at around $24^{\circ} \mathrm{C}$ and a rise from 26 to $31^{\circ} \mathrm{C}$ (Fig. 7C). The chlorophyll- $a$ 476 concentration relationship also increased, and the backscatter value was higher with higher 477 chlorophyll- $a$ concentrations (Fig. 7D). The relationship with the $20^{\circ} \mathrm{C}$ isotherm decreased: 
478 the mean backscatter value was higher when the isotherm was shallower (Fig. 7E). All

479 relationships were significant according to GAMM outputs, and the variability through cross

480 validation was small over almost all the variable ranges, showing the robustness of the model

481 (Fig. 7).

\subsection{Predicted spatial distribution}

483 We defined the austral summer or warm season as the months of December, January and 484 February (DJF) and March, April and May (MAM) quarter periods, and the austral winter or 485 cold season as June, July and August (JJA) and September, October and November (SON) 486 quarters. This definition was chosen relative to the common knowledge of these seasons in 487 New Caledonia (Cravatte et al., 2015). Spatial predictions of the GAMM2-SVM hybrid488 model were highly homogenous across one season: DJF was very similar to MAM, and 489 identically for JJA and SON (Fig. 8A).

490 Generally, values were higher during the warm season, during which the distributions showed aggregations of high values in the central part of the EEZ in a wide strip area with a southeast to northwest orientation encompassing the main island and the Loyalty islands where there was a high confidence in the predictions (see Fig. 1 for island and reef names). The values were particularly high north of $22^{\circ} \mathrm{S}$ (Fig. 8A, DJF and MAM) and around the Chesterfield

495 Reefs. Values were lower in the southeastern corner of the EEZ. The channel between the 496 group - made up of the Chesterfield and Bellona reefs, and the Fairway-Lansdowne Bank, and the main island - was also predicted to have lower values.

498 During the cold season, values were lower in the north, close to the coast of the main island, 499 and in the south along the edges of the EEZ (Fig. 8A, JJA and SON). Highest values during 500 the cold season were located south of $20^{\circ} \mathrm{S}$, south of the main island and the Chesterfield 501 Reefs, and north of the southeast corner of the EEW where there was a higher prediction 502 divergence between the models GAMM2 and SVM and, thus, less confidence was given to 503 the results in this area. Along the southwest coast of the main island, values were higher 504 farther towards the coast than during the warm season.

505 There was good agreement between the predictions of the two models (coefficient of variation 506 ranges from 0 to 7\%) for most of the EEZ (Fig. 8B). However, discrepancies between the 507 GAMM2 and SVM models were observed in some areas, with relatively high model 
coefficients of variation in the north of the EEZ, in the north of the southeastern corner of the EEZ, and the Fairway-Lansdowne Bank for the cold season, and north of the main island for the warm season. Using a $6 \%$ threshold for the coefficient of variation removed only $0.17 \%$ of the cells $(0.084 \%$ for DJF, $0.034 \%$ for MAM, $0.53 \%$ for JJA and $0.042 \%$ for SON), whereas

$51228 \%$ of the cells were removed for a $2 \%$ threshold for the coefficient of variation $(31 \%$ for 513 DJF, 30\% for MAM, 27\% for JJA and 22\% for SON).

A
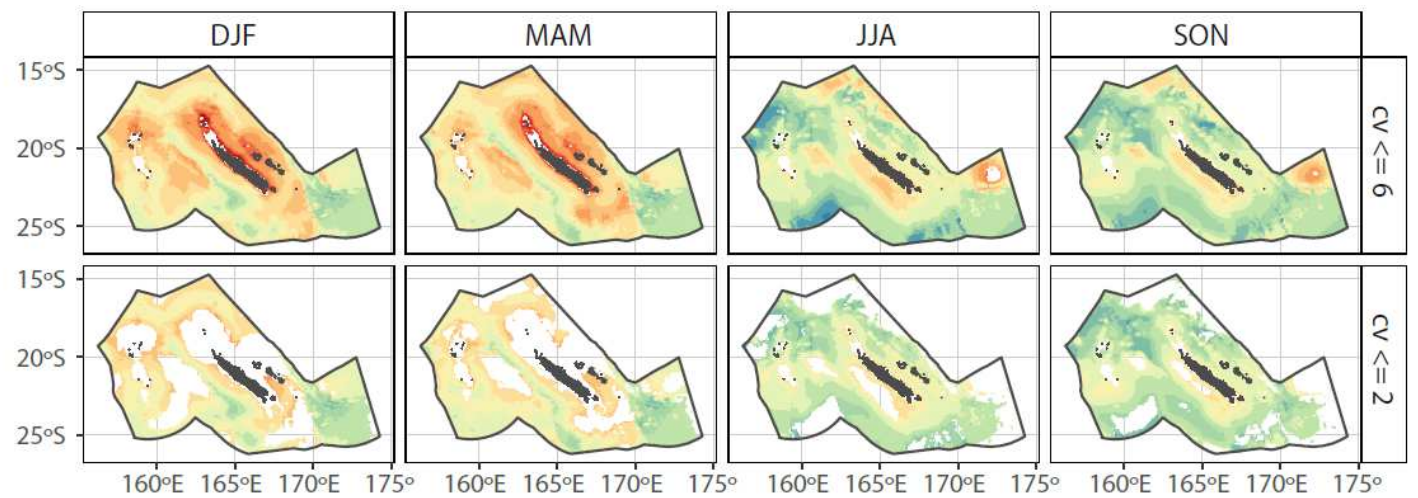

Mean corrected predicted Sv by GAMM and SVM (dB)

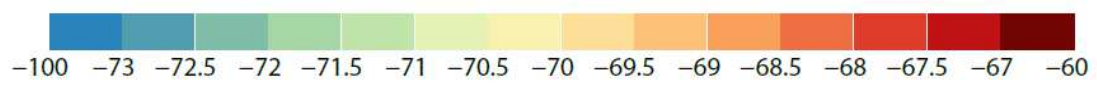

B

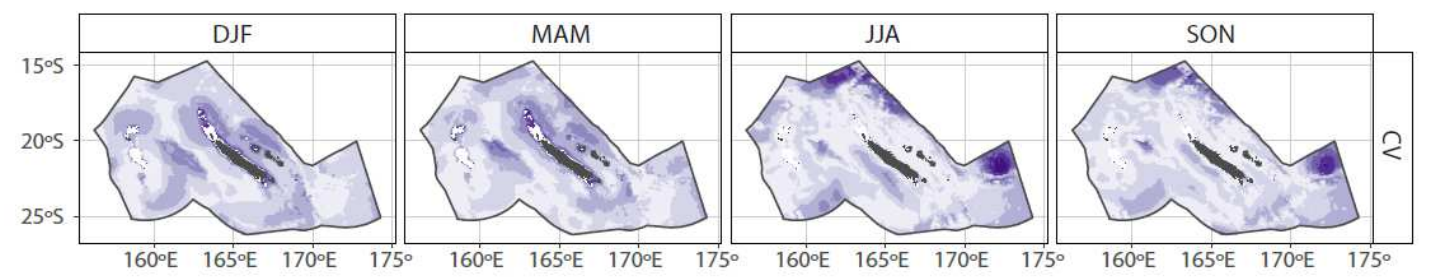

Variation coefficient (\%)

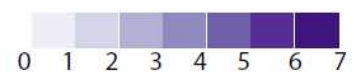

515 Figure 8: Corrected backscatter values at night predicted on average by GAMM2 and SVM1 in the exclusive economic zone of New Caledonia by quarter, with two different thresholds applied to coefficient of variation (panel A, top row: $6 \%$, bottom row: $2 \%$ ), and the associated coefficient of variation (panel B). Warm season: DJF (December, January, February) and MAM (March, April, May) and cold season: JJA (June, July, August) and SON (September, October, November).

\subsection{Comparison with SEAPODYM-MTL}

521 The correlation between the observed 20-120 m backscatter and SEAPODYM-MTL values,

522 extracted for the dates and locations of the cruise tracks was close to zero and non-significant,

523 suggesting an absence of direct coherence between the two sources. We then compared the 524 seasonal patterns of the output of the GAMM2-SVM gridded predicted model of backscatter 525 to seasonal SEAPODYM-MTL outputs. The warm and cold seasons were calculated as the 
526 averages of the two quarters composing each season. Within each season, we kept the data

527 with $\mathrm{CV}<=6 \%$ to keep the largest dataset in the hybrid model.

528 During the cold season (June to November) the GAMM2-SVM and the SEAPODYM-MTL models showed different spatial patterns (Fig. 9A). In SEAPODYM-MTL simulations, high

530 values were located in the southern part of the EEZ in oceanic waters close to the EEZ 531 boundary, while in the GAMM2-SVM model, this area was characterized by low values, 532 while high values occurred close to the south coast of the main island. However, in the two 533 cases, values were low in the northern part of the EEZ. During the warm season (December to 534 May), the SEAPODYM-MTL spatial distribution pattern was similar to the SEAPODYM535 MTL austral winter pattern with enhanced values. The difference between SEAPODYM536 MTL and GAMM2-SVM predictions based on observed acoustic data was stronger during the 537 warm season than during the cold season, with higher values found around islands and reefs 538 in the GAMM2-SVM predictions. For the two seasons, the SEAPODYM-MTL spatial 539 distribution showed a north-south gradient that the acoustic data did not show. The spatial 540 structures provided by the GAMM2-SVM predictions were spatially more detailed than in the 541 SEAPODYM-MTL predictions. For the two seasons, the Spearman correlations were very 542 low (<0.2). In SEAPODYM-MTL, the predicted biomass level changed but the spatial 543 distribution stayed similar over seasons, whereas in the GAMM2-SVM predictions, a spatial 544 distribution change over the seasonal cycle was observed as was a change in the mean level.

545 The seasonal cycle coming from the GAMM2-SVM hybrid model showed increased acoustic 546 density during the austral summer, and decreased density during the austral winter (Fig. 9B). 547 The seasonal cycle showed an approximate three-month lag between the GAMM2-SVM 548 predictions, and the SEAPODYM-MTL and seasonal variability was much weaker in 549 SEAPODYM-MTL than in the GAMM2-SVM predictions. The peak was in December for 550 SEAPODYM-MTL (averaged scaled values over the EEZ), while the highest peak was, on 551 average, in February for GAMM2-SVM outputs (Fig. 9B). The seasonal cycle from acoustic 552 data was mainly driven by change in the north of the EEZ, while the SEAPODYM seasonal 553 cycle seemed to be due to change in the biomass level in both the north and the south (Fig. 554 9A). 


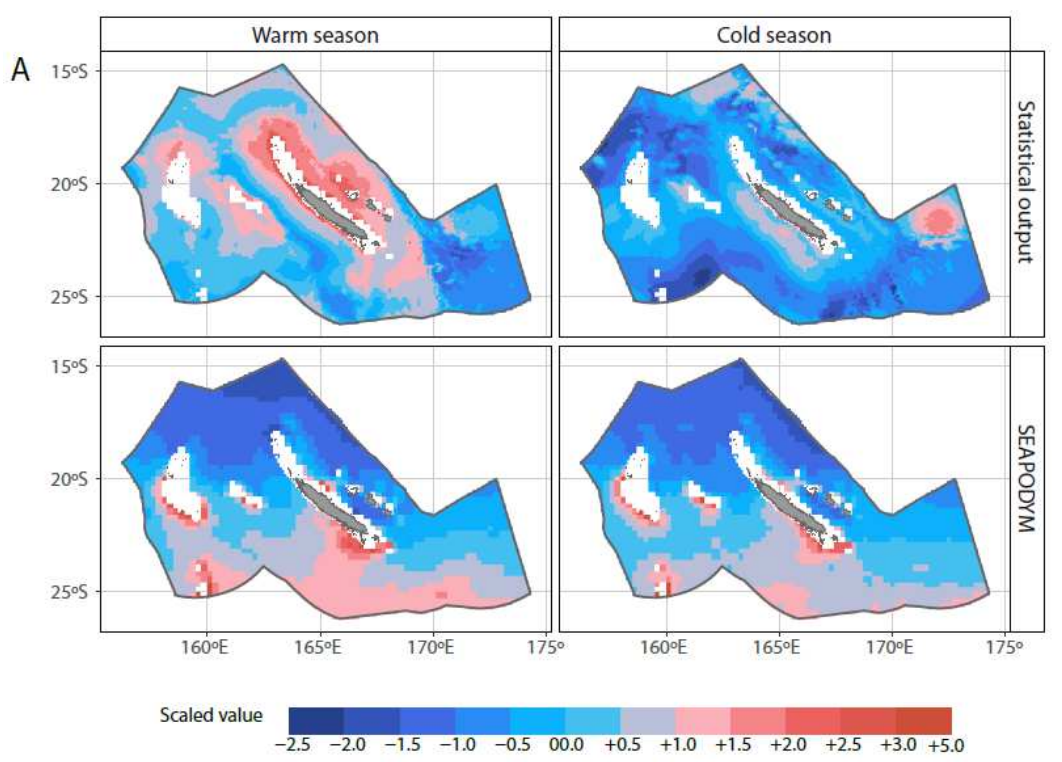

B

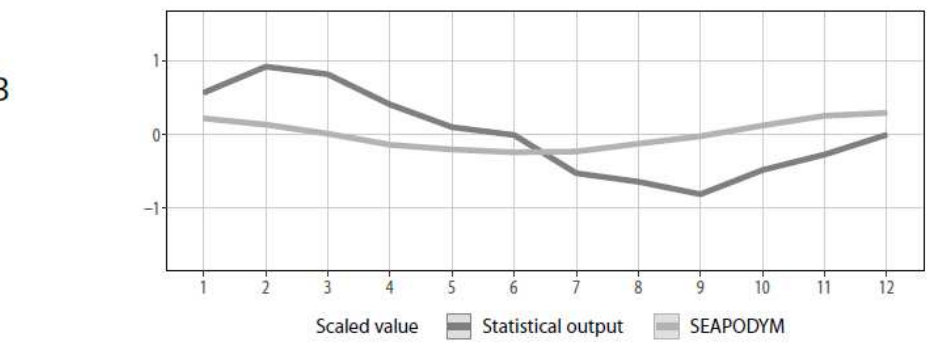

556 Figure 9: Corrected backscatter values predicted, on average, for the hybrid GAMM2-SVM model 557 with a coefficient of variation inferior to 6\% (statistical output, panel A, top row), and SEAPODYM558 MTL model (panel A, bottom) averaged by season. Only cells predicted by SEAPODYM-MTL are shown in both rows of panel A. The same data are averaged by month (panel B). Values on the three panels are scaled and centered for comparison.

\section{Discussion}

Backscatter values from 54 ADCP surveys at $75 \mathrm{kHz}$ and $150 \mathrm{kHz}$ over 19 years (1999-2017) were used to examine micronekton dynamics in the upper $120 \mathrm{~m}$ of the ocean in New Caledonia's EEZ (southwest Pacific), assuming that micronekton density was proportional to backscatter values. A strong diel signal was found as well as a clear seasonal cycle, an impact of El Niño, and a sign of a longer-term temporal trend. The link to environmental variables such as SST, surface chlorophyll- $a$, depth of the $20^{\circ} \mathrm{C}$ isotherm, bathymetry, and distance to the coast were studied. A hybrid model constructed with two statistical models (GAMM2 and SVM) was used for predictive statistical modelling of backscatter values. A large variability in spatial distribution was found over the seasons. Those spatial distributions were quite different from separate SEAPODYM-MTL model simulations. 


\subsection{ADCP-EK60 comparison}

573 The lag between mean ADCP levels was relatively large, about $20 \mathrm{~dB}$. Due to the absence of

574 a similar offset among EK60 Nectalis data (Fig. 3), this lag was linked to the reported ADCP

575 device and not to a biological effect. High positive correlations between the $70 \mathrm{kHz} \mathrm{S}_{\mathrm{V}_{-} \text {EK60 }}$ and the $150 \mathrm{kHz}$ and $75 \mathrm{kHz} \mathrm{S}_{\mathrm{v}_{-} \mathrm{ADCP}}$ have been previously observed in other regions (e.g., Brierley et al., 1998; Griffiths, 1996). Based on the positive correlations, data from both ADCP devices could be combined and analyzed as one dataset when adjusted to a common EK60 reference. With this methodology, we studied data from the ADCP at different frequencies to obtain a long time series for the present region (19 years by aggregating data from the two devices, including 12 years for the $150 \mathrm{kHz}$ ADCP and 7 years for the $75 \mathrm{kHz}$ $\mathrm{ADCP})$.

583 Although the relationships with the EK60 reference signal allowed us to combine data from the two ADCP devices, uncertainty remained among cruises using the same ADCP device. By analyzing the 54 cruises together, the methodology assumed that cruises performed with each ADCP device (38 cruises for the $150 \mathrm{kHz}$ device and 16 cruises for the $75 \mathrm{kHz}$ device) were comparable (i.e., the relationships found between $\mathrm{Sv}$ and environmental variables or across time were due to biological changes and were not linked to a device's temperature dependence for example). We based this hypothesis on previous studies where several ADCP cruises were aggregated to analyze them together (e.g., Ashjian et al., 2002; Bianchi and Mislan, 2016; Blanc et al., 2008; Chereskin and Tarling, 2007; Kaneda et al., 2002; Liljebladh and Thomasson, 2001; Radenac et al., 2010; Tarling et al., 2001). Moreover, regression curves for the EK60 signal for one cruise (one color on Fig. 3) were linear, whereas the cruises covered areas including large variations of temperature, particularly between the north and south of the EEZ (Fig. 1). This analysis indicated a constant survey-dependent shift rather than an environmental effect such as a device dependence to temperature. Finally, we had no other choice than to use a unique set of estimated regression parameters for all the cruises as only six cruises with EK60 data were available. For future studies using S-ADCPs, we recommend recording EK60 reference transects at least once a year for calibration.

600 While the size-range of organisms detected by ADCP was not defined precisely, both ADCP 601 devices were thought to detect a broad range of organisms from macrozooplankton to 602 micronekton in the 20-120 m layer. Smeti et al. (2015), using data from zooplankton nets and 603 TAPS (Tracor Acoustic Profiling System), concluded that a $150 \mathrm{kHz}$ ADCP is appropriate for 26 
604 detecting organisms such as macrozooplankton. The very high correlations of the ADCP

605 signal with the EK60 at various frequencies as presented in Menkes et al. (2015) and in the 606 present study, confirm the contribution of the micronekton to the 70 and $75 \mathrm{kHz} \mathrm{ADCP}$ 607 backscatter.

\section{$608 \quad 4.2$ Environmental predictors}

609 All relationships between ADCP backscatter and environmental variables had relatively

610 simple and smooth shapes.

611 The relationship between SST and $S_{v}$ was non-linearly increasing, reaching a first maximum 612 at $23.5^{\circ} \mathrm{C}$ and a second above $26^{\circ} \mathrm{C}$. Fewer SST values were sampled above $28^{\circ} \mathrm{C}$, and so the 613 relationship above $28^{\circ} \mathrm{C}$ was assumed with caution. This type of relationship with two 614 temperature optima may express contrasted situations either spatially (e.g., as in Boersch615 Supan et al., 2015) or by season as observed in the Gulf of Maine (Hazen et al., 2009). In the 616 present study, it seemed due to a clear difference between warm and cold seasons but also 617 between north and south regions.

618 The relationship between backscatter and chlorophyll- $a$ (a proxy for primary production) 619 showed an increase, with a plateau at higher values. Escobar-Flores et al. (2013) found a 620 strong correlation with chlorophyll- $a$ and the acoustic backscatter at the scale of the entire 621 South Pacific. However, they obtained a bell-shaped relationship instead of the plateau 622 predicted in the present study. Their maximum backscatter was obtained for a $\sim 0.5 \mathrm{mg}^{-\mathrm{mm}^{-3}}$ 623 chlorophyll- $a$ concentration, very similar to the present asymptotic chlorophyll- $a$ 624 concentration value. At the global scale, a similar strong positive link was found between the $62538 \mathrm{kHz}$ acoustic backscatter (EK60 echosounder) in the mesopelagic layer and satellite626 derived primary production (Irigoien et al., 2014). However, Boersch-Supan et al. (2015) in 627 the Indian Ocean, and Hazen and Johnston (2010) in the central equatorial Pacific, did not 628 find such significant relationships, suggesting that relationships may be ecosystem- or region629 dependent. In any case, understanding the mechanisms linking chlorophyll- $a$ or primary 630 productivity and micronekton requires the understanding of the intermediate zooplankton 631 compartment; accordingly, measuring phytoplankton, zooplankton and micronekton 632 simultaneously is required to better understand interactions in the lower trophic levels. 
633 Backscatter values decreased gradually with increasing distance from the coast, and during

634 the warm season (DJF and MAM), backscatter values increased with increasing proximity to

635 the reef. This pattern was observed both for the main island and for the Chesterfield Reefs,

636 and could be linked to an intensification of primary productivity close to the coast, and

637 conversely more patchiness offshore (Escobar-Flores et al., 2013). Shallow waters offer a

638 reduced habitat for mesopelagic organisms and induces a densification of the different

639 functional groups that they constitute (Escobar-Flores et al., 2018; Lehodey et al., 2010). Low

640 backscatter values far from the reef could also be due to changes in species composition, with

641 species responding differently to acoustic frequencies. For example, in the Southern Ocean, a

642 clear change in species composition was observed between the neritic zone and oceanic zone

643 (Duhamel et al., 2000; Koubbi et al., 2011). In the Southern California Bight, Davison et al.

644 (2015a) observed what they called a "seasonal basin effect", which they found to be

645 consistent with blooms of the siphonophore Nanomia bijuga. In the Southern Ocean between

646 New Zealand and the Ross Sea, Escobar-Flores et al. (2018) found that while the backscatter

$647(38 \mathrm{kHz})$ consistently and significantly decreased from north to south, a higher biomass of

648 mesopelagic fish was estimated from net sampling in the central region. Clearly, in absence of

649 in situ sampling, the acoustic data alone may be misleading.

650 Bathymetry and distance from the coast were not correlated because of the complexity of the sea bed within New Caledonia's EEZ (Appendix C). The relationship between backscatter and bottom depth showed an optimum of around $2000 \mathrm{~m}$ depth. The areas with a bottom

653 depth between $1500 \mathrm{~m}$ and $2500 \mathrm{~m}$ were located between the main island and the Loyalty

654 Islands, south of the main island, around the Chesterfield and Bellona reefs, and the Fairway-

655 Lansdowne Bank, and included seamounts (Appendix C, Fig. C2). Seamounts may aggregate micronekton as demonstrated by other studies, but highly depending on the type of seamount (e.g., shape and depth, presence of upwelling) and the type of organisms as not all species aggregate around seamounts (Annasawmy et al., 2019; Drazen et al., 2011; Morato et al., 2010, 2008). From our study, a direct seamount aggregation effect was not highlighted. To understand the effect of seamounts on micronekton aggregation, a better characterization of seamounts would be necessary, including considering variables such as distance to the seamount and typology (e.g., depth of the summit, shallow or deep, sharp or flat morphology).

663 Higher backscatter values were found when the $20^{\circ} \mathrm{C}$ isotherm was closer to the surface, but 664 with a larger confidence interval before 150-m depth and after $250 \mathrm{~m}$ where sampled values 
were more scattered. The depth of the $20^{\circ} \mathrm{C}$ isotherm is a proxy for the thermocline location.

666 A deep $20^{\circ} \mathrm{C}$ isotherm (and thus thermocline) likely limits possible nutrients inputs in the euphotic surface layer (Kessler and Cravatte, 2013). On the contrary, the closer the $20^{\circ} \mathrm{C}$ isotherm is to the surface, the higher the vertical mixing is in the surface layers, bringing more nutrients to the photic layer, thus making the surface layer more productive. This productivity increase propagates through the food web as potentially detected here and in other studies (Benoit-Bird and McManus, 2012; Lebourges-Dhaussy et al., 2014). Therefore, together with biogeochemical variables and sea surface temperature, the $20^{\circ} \mathrm{C}$ isotherm appears to be a useful proxy for the thermocline in the context of climate change to understand and monitor the impacts of increased temperature and vertical stratification of the water column on prey availability for top predators (Ceccarelli et al., 2013; Choy et al., 2016).

The $20^{\circ} \mathrm{C}$ isotherm is also used to characterize mesoscale activity with deeper closed-contours of the $20^{\circ} \mathrm{C}$ isotherm characterizing anticyclonic "downwelling-type" eddies, and shallower $20^{\circ} \mathrm{C}$ closed-contours isotherms characterizing cyclonic "upwelling-type" eddies. Eddy activity is relatively important around New Caledonia. Previous studies have demonstrated a positive impact of eddies on primary production (Chelton et al., 2011; Gaube and McGillicuddy, 2017; McGillicuddy et al., 2007) and some impacts on zooplankton (Goldthwait and Steinberg, 2008; Hauss et al., 2016; Lebourges-Dhaussy et al., 2014). The relationship with micronekton is less clear and sometimes contradictory or specifically related to observed eddies (Behagle et al., 2014; Brandt, 1983; Griffiths and Wadley, 1986; Sabarros et al., 2009). Further studies to determine how eddies affect backscatter and micronekton should include specific metrics to eventually propose a typology.

687 Finally, we did not test a possible effect associated with the dissolved oxygen concentration

688 because oxygen is not limiting in this subtropical zone. Further, although oxygen is especially important for the maximum depth of migration (Bertrand et al., 2010; Bianchi et al., 2013;

690 Maas et al., 2014), that was not a parameter considered in this study as we limited our 691 analyses to nighttime abundance within the 20-120m layer.

\subsubsection{Mean spatial distribution}

694 Without an independent dataset to validate our predicted distributions, the use of two different 695 modeling approaches offered an alternative to assess prediction robustness. GAMMs have 
been largely used to explain backscatter value variability with environmental data (Bertrand et

697 al., 2004; Boersch-Supan et al., 2015; Escobar-Flores et al., 2018; Hazen and Johnston, 2010).

698 Machine-learning algorithms such as SVM have been used for species distribution modeling

699 (Drake et al., 2006) but not yet applied to acoustic data. One major difference between models

700 was how they dealt with interaction terms: GAMM relationships between $S_{v}$ and

701 environmental variables had the same shape for the two ADCP devices, whereas SVM

702 relationships had different shapes. The underlying assumption was that depending on the

703 ADCP frequency, organisms respond differently and thus show different responses to oceanographic variables. As the reality was unknown and as quadratic errors for the two models were very close, assuming common patterns seemed to be reasonable: the use of two methods concurrently increased the predictions confidence. Predicted spatial patterns were coherent with the model based on GAMM1, which included latitude and longitude instead of environmental predictive variables (Appendix D, Fig. D1). However, acoustic data remained relatively complicated to analyze due to the high collinearity, and difficult to interpret due to a persistent uncertainty about which organisms were being measured.

711 The two approaches, GAM and SVM, generally agreed with one another with some 712 exceptions. Both models predicted higher backscatter close to reefs during the warm season, 713 and in the southern part of the EEZ during the cold season. These areas were characterized by 714 high chlorophyll- $a$ concentration, warm water, close to the coast, and optimum bathymetry. 715 The main island's western coast seemed to be a favorable habitat year round. On the contrary, 716 low predicted backscatter values in the EEZ's south during the austral winter (Fig. 8A) were 717 in waters with the highest chlorophyll- $a$ concentration (Appendix C). SST may be too low, 718 despite high chlorophyll- $a$ concentrations, to be favorable to backscatter values. The combination of all intertwined environmental parameters determined the backscatter value at 720 a specific location and time, defining micronekton habitat.

721 The areas where the two models diverged the most were the northern part of the southeast 722 corner of the EEZ, the Fairway-Lansdowne Bank, and the northern part of the EEZ. Those 723 areas had all been sampled several times (Fig. 1). The high variability predicted by models 724 could be linked to the large variability in oceanographic variables used as predictors or could 725 be linked to large variability in observed scattering values in a region with shallow bottom 726 depths. 
730 Not surprisingly, the largest variability in abundance of micronekton $(20-120 \mathrm{~m})$ was 731 associated with the DVM, a well-known ubiquitous phenomenon (Bianchi and Mislan, 2016).

732 Sun elevation was found to explain the largest part of $S_{\mathrm{V}_{-} \mathrm{ADCP}}$ variability, with higher values

733 during the night than during the day. $S_{\mathrm{V}_{-} \mathrm{ADCP}}$ became constant across a 24-hour cycle when 734 sun elevation was lower than $-20^{\circ}$ at night and higher than $10^{\circ}$ during the day. Sun elevation 735 threshold values were close to the values used in SEAPODYM-MTL to define a "night 736 period" and a "day period" (Lehodey et al., 2015). The difference in the mean backscatter 737 value between night and day was in agreement with previous results (Domokos, 2009).

738 Backscatter echo intensity was globally higher during the warm season (February-March) and 739 lower during the cold season (July-August) with a clear seasonal cycle both by the GAMM1 740 results (Fig. 5) and the second hybrid GAMM2/SVM. Secondary peaks in the seasonal cycle could be explained by different rates of recruitment and mortality according to the species, and thus different optima induce different peaks in species abundance over the year. This

743 hypothesis was reinforced by the fact that areas predicted as having favorable habitat changed 744 across the year (Fig. 8A), and may be due to favorable habitat for different species. Such 745 variability could be expected given the high diversity of micronekton observed in the region, 746 where more than 480 species of fishes, crustaceans, squids and gelatinous organisms have 747 been recorded (Payri, 2018).

748 A significant influence of ENSO on acoustic densities was detected in the EEZ, with higher 749 values during El Niño than La Niña or neutral years. We showed that micronekton density 750 increased with both increasing surface chlorophyll- $a$ and SST (Fig. 7). In the EEZ, El Niño is 751 characterized by colder SSTs (Delcroix and Lenormand, 1997) but more productive waters 752 (Dandonneau and Gohin, 1984; Radenac et al., 2012). Therefore, we suggested that the 753 chlorophyll- $a$ effect (positive anomaly) associated with El Niño was stronger than the effect 754 of SST (negative anomaly), explaining the higher backscatter during El Niño. Additionally, 755 we knew that ENSO could have an impact on micronekton species, especially on their 756 recruitment (Hewitt et al., 2003; Quetin and Ross, 2003). Such mechanisms also likely 757 occurred in New Caledonia's waters. 
An interesting long-term temporal trend was finally observed over the 1999-2017 time period, with eight years of acoustic density decrease from 1999 to 2007, followed by eight years of increase from 2007 to 2015 (Fig. 6). This trend could be related to the IPO/PDO cycle (Interdecadal Pacific Oscillation/Pacific Decadal Oscillation). PDO fluctuations have basin-wide effects on SST and thermocline slope that are similar to El Niño (warm phase) and La Niña (cold phase) but on an approximately 10-year cycle (Mantua and Hare, 2002). A PDO warm period started in 2008 and coincided with the increasing trend of backscatter values. However, we did not identify any related long-term anomaly in the oceanographic variables used as predictors in this study, and the shift in backscatter after 2007 remained unexplained.

\subsection{Interest for ecosystem modeling}

The predicted backscatter was compared to micronekton biomass from the ecosystem model SEAPODYM for the functional groups inhabiting the epipelagic layer during the nighttime. If we assume that backscatter was directly proportional to the biomass of all micronekton organisms included in these functional groups, a good match between the two products would provide confidence in the results of both the ecosystem model and the statistical approach used to inter-calibrate and merge a large volume of acoustic data collected with ADCP. This was not the case, however. Micronekton SEAPODYM biomass distribution in the epipelagic layer at night was close to the average distribution of chlorophyll- $a$, with higher productivity in the southern region (Fig. 9 and Appendix C4), but a delayed seasonal peak (NovemberDecember) of five months relative to the peak of chlorophyll- $a$ that occurs around JulyAugust (Condie and Dunn, 2006; Smeti et al., 2015). The predicted average backscatter had a seasonal peak in the warmest months (February-March), and higher values, on average, in the northern warmer region.

For a better understanding of these results, it seems essential to characterize the community of mesozooplankton and micronekton species in these different regions and seasons, the target strengths of dominant species at different frequencies and their cycles of abundances. It is possible for instance that the observed discrepancy between model outputs was due to seasonal blooms of gas-bearing siphonophores (Davison et al., 2015b; Proud et al., 2018) or similar organisms that have strong acoustic resonance but low energy (carbon) content. Conversely a large biomass of mesopelagic fish without gas-filled swim bladders may be present but transparent to the acoustic signal (Foote, 1980). 
Continuing to validate ecosystem models is another essential task. The SEAPODYM-MTL advection model may appear too simple to take into account the spatial variation of observed micronekton distribution across seasons, based on acoustic estimates. Implementing a zooplankton compartment in SEAPODYM-MTL may improve that model by giving more flexibility to the model to better fit with observed backscatter values.

795

Comparing ecosystem model outputs with equivalent observations such as acoustic data was challenging. The biomass of taxonomic groups defined in ecosystem models needs to be converted into measures suitable for comparison, in this case target strength, by making simple approximations of target shape and assumptions regarding density and sound speed contrasts (Lavery et al., 2007; Scoulding et al., 2015). This approach still requires collecting in situ data to attribute which part of the ecosystem model biomass is observable, or not, with a given acoustic frequency. A multi-platform approach to observation, combining nets, acoustics, imagery techniques and eDNA, appears necessary to achieve this goal (Handegard et al., 2013; Lehodey et al., 2015).

\subsection{Conclusions and perspectives}

Our results bring additional evidence that ADCP echosounders are a valuable source of data for studying the variability top predator prey through time and space, particularly macrozooplankton and micronekton. The access to a large historical ADCP acoustic database was of primary interest, especially in the context of climate change, to explore past variability. We provided an approach to merge two un-calibrated acoustic datasets using a reference calibrated dataset. Key environmental predictors such as SST, chlorophyll- $a$, thermocline depth, bathymetry and distance from coast seemed sufficient to statistically predict the backscattering intensity recorded from ADCP in New Caledonia's EEZ. The temporal and spatial variability of the signal were analyzed and provide interesting results at seasonal, interannual (ENSO) and long-term scales. Finally, we showed that a state-of-the-art model (SEAPODYM-MTL) did not always reproduce acoustic estimates. To be fully comparable with ecosystem model outputs, a research effort on the development of acoustic observation models is needed. Acoustic data need to be complemented with multiple observation platforms to reduce overall bias in estimates of micronekton biomass. The resulting estimates can be used to assess, initiate and assimilate into ecosystem models. 
820 Continuous and long-term marine ecosystem monitoring at various spatial and temporal scales

821 has multiple applications in the domains of ecosystem-based fishery management, marine

822 spatial planning, conservation and monitoring of climate change (Kloser et al., 2009).

823 The case of New Caledonia and the implementation of the Coral Sea Natural Park 824 (https://mer-de-corail.gouv.nc/) provides a good example of a close link between science and 825 management. Observed and predicted distributions of micronekton along with the knowledge 826 of top predator distributions are central to refining management and conservation measures in 827 such a vast oceanic region. Cooperation and coordination at a larger international scale is also 828 highly desirable, such as through the Global Ocean Observing System (GOOS), to model and 829 forecast the impact of the climate change on the functioning of the ecosystems and to support 830 development of long term mitigation and conservation measures (Bax et al., 2018; Muller831 Karger et al., 2018).

\section{Acknowledgements}

836 This document has been produced with financial assistance from the European Union. The

837 contents of this document are the sole responsibility of A. Receveur, and can under no 838 circumstance be regarded as reflecting the position of the European Union. We thank R/V Alis 839 officers and crew, and science parties who participated in the cruises where data are included 840 in the present paper. This work was supported by the French national program LEFE/INSU 841 (Les Enveloppes fluides de l'environnement/Institut national des sciences de l'Univers). 842 Finally, we thank IRD (Institut de recherche pour le développement) and the Pacific 843 Community for their support.

\section{References}

845 Allain, V., Fernandez, E., Hoyle, S.D., Caillot, S., Jurado-Molina, J., Andréfouët, S., Nicol, S.J., 2012. Interaction between Coastal and Oceanic Ecosystems of the Western and Central Pacific Ocean through Predator-Prey Relationship Studies. PLoS ONE 7, 848 e36701. https://doi.org/10.1371/journal.pone.0036701 
Alory, G., Vega, A., Ganachaud, A., Despinoy, M., 2006. Influence of upwelling, subsurface stratification, and heat fluxes on coastal sea surface temperature off southwestern New Caledonia. Journal of Geophysical Research 111, C07023. https://doi.org/10.1029/2005JC003401

Andréfouët, S., chagnaud, N., Chauvin, C., Kranenburg, C.J., 2008. Atlas of French Overseas Coral Reefs.

Annasawmy, P., Ternon, J.-F., Cotel, P., Cherel, Y., Romanov, E.V., Roudaut, G., LebourgesDhaussy, A., Ménard, F., Marsac, F., 2019. Micronekton distributions and assemblages at two shallow seamounts of the south-western Indian Ocean: Insights from acoustics and mesopelagic trawl data. Progress in Oceanography 102161. https://doi.org/10.1016/j.pocean.2019.102161

Ariza, A., Garijo, J.C., Landeira, J.M., Bordes, F., Hernández-León, S., 2015. Migrant biomass and respiratory carbon flux by zooplankton and micronekton in the subtropical northeast Atlantic Ocean (Canary Islands). Progress in Oceanography 134, 330-342. https://doi.org/10.1016/j.pocean.2015.03.003

Ariza, A., Landeira, J.M., Escánez, A., Wienerroither, R., Aguilar de Soto, N., Røstad, A., Kaartvedt, S., Hernández-León, S., 2016. Vertical distribution, composition and migratory patterns of acoustic scattering layers in the Canary Islands. Journal of Marine Systems 157, 82-91. https://doi.org/10.1016/j.jmarsys.2016.01.004

Ashjian, C.J., Smith, S.L., Flagg, C.N., Idrisi, N., 2002. Distribution, annual cycle, and vertical migration of acoustically derived biomass in the Arabian Sea during 19941995. Deep Sea Research Part II: Topical Studies in Oceanography 49, 2377-2402. https://doi.org/10.1016/S0967-0645(02)00041-3

Bax, N.J., Appeltans, W., Brainard, R., Duffy, J.E., Dunstan, P., Hanich, Q., Harden Davies, H., Hills, J., Miloslavich, P., Muller-Karger, F.E., Simmons, S., Aburto-Oropeza, O., Batten, S., Benedetti-Cecchi, L., Checkley, D., Chiba, S., Fischer, A., Andersen Garcia, M., Gunn, J., Klein, E., Kudela, R.M., Marsac, F., Obura, D., Shin, Y.-J., Sloyan, B., Tanhua, T., Wilkin, J., 2018. Linking Capacity Development to GOOS Monitoring Networks to Achieve Sustained Ocean Observation. Front. Mar. Sci. 5. https://doi.org/10.3389/fmars.2018.00346

Bedford, M., Melbourne-Thomas, J., Corney, S., Jarvis, T., Kelly, N., Constable, A., 2015. Prey-field use by a Southern Ocean top predator: enhanced understanding using integrated datasets. Marine Ecology Progress Series 526, 169-181. https://doi.org/10.3354/meps11203

Behagle, N., Cotté, C., Ryan, T.E., Gauthier, O., Roudaut, G., Brehmer, P., Josse, E., Cherel, Y., 2016. Acoustic micronektonic distribution is structured by macroscale oceanographic processes across $20-50^{\circ} \mathrm{S}$ latitudes in the South-Western Indian Ocean. Deep Sea Research Part I: Oceanographic Research Papers 110, 20-32. https://doi.org/10.1016/j.dsr.2015.12.007

Behagle, N., du Buisson, L., Josse, E., Lebourges-Dhaussy, A., Roudaut, G., Ménard, F., 2014. Mesoscale features and micronekton in the Mozambique Channel: An acoustic approach. Deep Sea Research Part II: Topical Studies in Oceanography 100, 164-173. https://doi.org/10.1016/j.dsr2.2013.10.024

Bell, J.D., Allain, V., Allison, E.H., Andréfouët, S., Andrew, N.L., Batty, M.J., Blanc, M., Dambacher, J.M., Hampton, J., Hanich, Q., Harley, S., Lorrain, A., McCoy, M., McTurk, N., Nicol, S., Pilling, G., Point, D., Sharp, M.K., Vivili, P., Williams, P., 2015. Diversifying the use of tuna to improve food security and public health in Pacific Island countries and territories. Marine Policy 51, 584-591. 
897

898

899

900

901

902

903

904

905

906

907

908

909

910

911

912

913

914

915

916

917

918

919

920

921

922

923

924

925

926

927

928

929

930

931

932

933

934

935

936

937

938

939

940

941

942

943

944

945

946

Benoit-Bird, K.J., McManus, M.A., 2012. Bottom-up regulation of a pelagic community through spatial aggregations. Biology Letters 8, 813-816. https://doi.org/10.1098/rsbl.2012.0232

Benoit-Bird, K.J., Moline, M.A., Southall, B.L., 2017. Prey in oceanic sound scattering layers organize to get a little help from their friends: Schooling within sound scattering layers. Limnology and Oceanography 65:2788-2798. https://doi.org/10.1002/lno.10606

Bertrand, A., Ballón, M., Chaigneau, A., 2010. Acoustic Observation of Living Organisms Reveals the Upper Limit of the Oxygen Minimum Zone. PLoS ONE 5, e10330. https://doi.org/10.1371/journal.pone.0010330

Bertrand, A., Bard, F.-X., Josse, E., 2002. Tuna food habits related to the micronekton distribution in French Polynesia. Marine Biology 140, 1023-1037. https://doi.org/10.1007/s00227-001-0776-3

Bertrand, A., Segura, M., Gutiérrez, M., Vásquez, L., 2004. From small-scale habitat loopholes to decadal cycles: a habitat-based hypothesis explaining fluctuation in pelagic fish populations off Peru. Fish and fisheries 5, 296-316.

Bianchi, D., Galbraith, E.D., Carozza, D.A., Mislan, K.A.S., Stock, C.A., 2013. Intensification of open-ocean oxygen depletion by vertically migrating animals. Nature Geoscience 6, 545-548. https://doi.org/10.1038/ngeo1837

Bianchi, D., Mislan, K.A.S., 2016. Global patterns of diel vertical migration times and velocities from acoustic data: Global patterns of diel vertical migration. Limnology and Oceanography 61, 353-364. https://doi.org/10.1002//no.10219

Blanc, Ph., Wald, L., 2012. The SG2 algorithm for a fast and accurate computation of the position of the Sun for multi-decadal time period. Solar Energy 86, 3072-3083. https://doi.org/10.1016/j.solener.2012.07.018

Blanc, S., Baqués, M., Etcheverry de Milou, M.I., 2008. Examining the plankton acoustic response with a vessel mounted ADCP across oceanic fronts located in the Drake Passage. Asociación Argentina de Geofísicos y Geodestas 33, 110-121.

Boersch-Supan, P.H., Rogers, A.D., Brierley, A.S., 2015. The distribution of pelagic sound scattering layers across the southwest Indian Ocean. Deep Sea Research Part II: Topical Studies in Oceanography. https://doi.org/10.1016/j.dsr2.2015.06.023

Bohmann, K., Evans, A., Gilbert, M.T.P., Carvalho, G.R., Creer, S., Knapp, M., Yu, D.W., de Bruyn, M., 2014. Environmental DNA for wildlife biology and biodiversity monitoring. Trends in Ecology \& Evolution 29, 358-367. https://doi.org/10.1016/j.tree.2014.04.003

Brandt, S.B., 1983. Temporal and spatial patterns of lanternfish (family Myctophidae) communities associated with a warm-core eddy. Marine Biology 74, 231-244.

Brierley, A.S., Brandon, M.A., Watkins, J.L., 1998. An assessment of the utility of an acoustic Doppler current profiler for biomass estimation 19.

Brill, R.W., Bigelow, K.A., Musyl, M.K., Fritsches, K.A., Warrant, E.J., 2005. Bigeye tuna (Thunnus obesus) behavior and physiology and their relevance to stock assessments and fishery biology. Col. Vol. Sci. Pap. ICCAT 57, 142-161.

Browne, M.W., Cudeck, R., 1989. Single Sample Cross-Validation Indices for Covariance Structures. Multivariate Behavioral Research 24, 445-455. https://doi.org/10.1207/s15327906mbr2404_4

Burgos, J.M., Horne, J.K., 2008. Characterization and classification of acoustically detected fish spatial distributions. ICES Journal of Marine Science 65, 1235-1247.

Cade, D.E., Benoit-Bird, K.J., 2015. Depths, migration rates and environmental associations of acoustic scattering layers in the Gulf of California. Deep Sea Research Part I: Oceanographic Research Papers 102, 78-89. https://doi.org/10.1016/j.dsr.2015.05.001 
Ceccarelli, D.M., McKinnon, A.D., Andréfouët, S., Allain, V., Young, J., Gledhill, D.C., Flynn, A., Bax, N.J., Beaman, R., Borsa, P., Brinkman, R., Bustamante, R.H., Campbell, R., Cappo, M., Cravatte, S., D’Agata, S., Dichmont, C.M., Dunstan, P.K., Dupouy, C., Edgar, G., Farman, R., Furnas, M., Garrigue, C., Hutton, T., Kulbicki, M., Letourneur, Y., Lindsay, D., Menkes, C., Mouillot, D., Parravicini, V., Payri, C., Pelletier, B., Richer de Forges, B., Ridgway, K., Rodier, M., Samadi, S., Schoeman, D., Skewes, T., Swearer, S., Vigliola, L., Wantiez, L., Williams, Alan, Williams, Ashley, Richardson, A.J., 2013. The Coral Sea, in: Advances in Marine Biology. Elsevier, pp. 213-290. https://doi.org/10.1016/B978-0-12-408096-6.00004-3

Chelton, D.B., Gaube, P., Schlax, M.G., Early, J.J., Samelson, R.M., 2011. The Influence of Nonlinear Mesoscale Eddies on Near-Surface Oceanic Chlorophyll. Science 334, 328 332. https://doi.org/10.1126/science.1208897

Chereskin, T.K., Tarling, G.A., 2007. Interannual to diurnal variability in the near-surface scattering layer in Drake Passage. ICES Journal of Marine Science 64, 1617-1626. https://doi.org/10.1093/icesjms/fsm138

Condie, S.A., Dunn, J.R., 2006. Seasonal characteristics of the surface mixed layer in the Australasian region: implications for primary production regimes and biogeography. Marine and Freshwater Research 57, 569-590. https://doi.org/10.1071/MF06009

Cortes, C., Vapnik, V., 1995. Support-vector networks. Mach Learn 20, 273-297. https://doi.org/10.1007/BF00994018

Cravatte, S., Kestenare, E., Eldin, G., Ganachaud, A., Lefevre, J., Marin, F., Menkes, C., Aucan, J., 2015. Regional circulation around New Caledonia from two decades of observations. Journal of Marine Systems 148, 249-271. https://doi.org/10.1016/j.jmarsys.2015.03.004

Dandonneau, Y., Gohin, F., 1984. Meridional and seasonal variations of the sea surface chlorophyll concentration in the southwestern tropical Pacific (14 to $32^{\circ} \mathrm{S}, 160$ to $175^{\circ}$ E). Deep Sea Research Part A. Oceanographic Research Papers 31, 1377-1393. https://doi.org/10.1016/0198-0149(84)90078-5

Davison, P., Lara-Lopez, A., Anthony Koslow, J., 2015a. Mesopelagic fish biomass in the southern California current ecosystem. Deep Sea Research Part II: Topical Studies in Oceanography 112, 129-142. https://doi.org/10.1016/j.dsr2.2014.10.007

Davison, P.C., Koslow, J.A., Kloser, R.J., 2015b. Acoustic biomass estimation of mesopelagic fish: backscattering from individuals, populations, and communities. ICES Journal of Marine Science 72, 1413-1424. https://doi.org/10.1093/icesjms/fsv023

Deines, K.L., 1999. Backscatter estimation using Braodband Acoustic Doppler Current Profiles. Presented at the Sixth working conf on current measurement, san diego, CA.

Delcroix, T., Lenormand, O., 1997. ENSO signals in the vicinity of New Caledonia, South Western Pacific. Oceanologica Acta 20, 481-491.

Domokos, R., 2009. Environmental effects on forage and longline fishery performance for albacore (Thunnus alalunga) in the American Samoa Exclusive Economic Zone. Fisheries Oceanography 18, 419-438. https://doi.org/10.1111/j.13652419.2009.00521.x

Dormann, C., McPherson, J., Araújo, M., Bivand, R., Bolliger, J., Carl, G., Davies, R., Hirzel, A., Jetz, W., Daniel Kissling, W., Kühn, I., Ohlemüller, R., Peres-Neto, P., Reineking, B., Schröder, B., Schurr, F., Wilson, R., 2007. Methods to account for spatial autocorrelation in the analysis of species distributional data: a review. Ecography 30, 609-628. https://doi.org/10.1111/j.2007.0906-7590.05171.x 
1002

1003

1004

1005

1006

1007

1008

1009

1010

1011

1012

1013

1014

1015

1016

1017

1018

1019

1020

1021

1022

1023

1024

1025

1026

1027

1028

1029

1030

1031

1032

1033

1034

1035

1036

1037

1038

1039

1040

1041

1042

Drake, J.M., Randin, C., Guisan, A., 2006. Modelling ecological niches with support vector machines. Journal of Applied Ecology 43, 424-432. https://doi.org/10.1111/j.13652664.2006.01141.x

Drazen, J.C., De Forest, L.G., Domokos, R., 2011. Micronekton abundance and biomass in Hawaiian waters as influenced by seamounts, eddies, and the moon. Deep Sea Research Part I: Oceanographic Research Papers 58, 557-566. https://doi.org/10.1016/j.dsr.2011.03.002

Drazen, J.C., Sutton, T.T., 2017. Dining in the Deep: The Feeding Ecology of Deep-Sea Fishes. Annual Review of Marine Science 9, 337-366. https://doi.org/10.1146/annurev-marine-010816-060543

Duffy, L.M., Kuhnert, P.M., Pethybridge, H.R., Young, J.W., Olson, R.J., Logan, J.M., Goñi, N., Romanov, E., Allain, V., Staudinger, M.D., Abecassis, M., Choy, C.A., Hobday, A.J., Simier, M., Galván-Magaña, F., Potier, M., Ménard, F., 2017. Global trophic ecology of yellowfin, bigeye, and albacore tunas: Understanding predation on micronekton communities at ocean-basin scales. Deep Sea Research Part II: Topical Studies in Oceanography 140, 55-73. https://doi.org/10.1016/j.dsr2.2017.03.003

Duhamel, G., Koubbi, P., Ravier, C., 2000. Day and night mesopelagic fish assemblages off the Kerguelen Islands (Southern Ocean). Polar Biol 23, 106-112. https://doi.org/10.1007/s003000050015

Escobar-Flores, P., O’Driscoll, R., Montgomery, J., 2013. Acoustic characterization of pelagic fish distribution across the South Pacific Ocean. Marine Ecology Progress Series 490, 169-183. https://doi.org/10.3354/meps10435

Escobar-Flores, P.C., O’Driscoll, R.L., Montgomery, J.C., 2018. Predicting distribution and relative abundance of mid-trophic level organisms using oceanographic parameters and acoustic backscatter. Marine Ecology Progress Series 592, 37-56. https://doi.org/10.3354/meps12519

Fiedler, P.C., Barlow, J., Gerrodette, T., 1998. Dolphin prey abuindance determined from acoustic backscatter data in eastern Pacific surveys. Fishery Bulletin 96, 237-247.

Flagg, C.N., Smith, S.L., 1989. On the use of the acoustic Doppler current profiler to measure zooplankton abundance. Deep Sea Research Part A. Oceanographic Research Papers 36, 455-474. https://doi.org/10.1016/0198-0149(89)90047-2

Foote, K.G., 1980. Importance of the swimbladder in acoustic scattering by fish: A comparison of gadoid and mackerel target strengths. The Journal of the Acoustical Society of America 67, 2084-2089. https://doi.org/10.1121/1.384452

Foote, K.G., Knudsen, H.P., Vestnes, G., 1987. Calibration of acoustic instruments for fish density estimation: a practical guide. Cooperative research report / International Council for the Exploration of the Sea 144.

Friedman, J.H., 2001. Greedy Function Approximation: A Gradient Boosting Machine. The Annals of Statistics 29, 1189-1232.

Ganachaud, A., Vega, A., Rodier, M., Dupouy, C., Maes, C., Marchesiello, P., Eldin, G., Ridgway, K., Le Borgne, R., 2010. Observed impact of upwelling events on water properties and biological activity off the southwest coast of New Caledonia. Marine Pollution Bulletin 61, 449-464. https://doi.org/10.1016/j.marpolbul.2010.06.042

Gardes, L., Tessier, E., Allain, V., Alloncle, N., Baudat-Franceschi, J., Butaud, J.-F., Collot, J., Etaix-Bonnin, R., Hubert, A., Jourdan, H., Loisier, A., Menkes, C., Payri, C., Rouillard, P., Samadi, S., Vidal, E., Yokohama, Y., 2014. Analyse stratégique de l'Espace maritime de la Nouvelle-Calédonie - vers une gestion intégrée. Agence des aires marines protégées / Gouvernement de la Nouvelle-Calédonie éditeurs. 
1043

1044

1045

1046

1047

1048

1049

1050

1051

1052

1053

1054

1055

1056

1057

1058

1059

1060

1061

1062

1063

1064

1065

1066

1067

1068

1069

1070

1071

1072

1073

1074

1075

1076

1077

1078

1079

1080

1081

1082

1083

1084

1085

1086

1087

1088

1089

1090

1091

Gaube, P., McGillicuddy, D.J., 2017. The influence of Gulf Stream eddies and meanders on near-surface chlorophyll. Deep Sea Research Part I: Oceanographic Research Papers 122, 1-16. https://doi.org/10.1016/j.dsr.2017.02.006

Giménez, J., Marçalo, A., García-Polo, M., García-Barón, I., Castillo, J.J., FernándezMaldonado, C., Saavedra, C., Santos, M.B., Stephanis, R., 2018. Feeding ecology of Mediterranean common dolphins: The importance of mesopelagic fish in the diet of an endangered subpopulation. Marine Mammal Science 34, 136-154. https://doi.org/10.1111/mms.12442

Gjøsaeter, J., Kawaguchi, K., 1980. A Review of the World Resources of Mesopelagic Fish. Food \& Agriculture Org.

Golding, N., Purse, B.V., 2016. Fast and flexible Bayesian species distribution modelling using Gaussian processes. Methods in Ecology and Evolution 7, 598-608. https://doi.org/10.1111/2041-210X.12523

Goldstein, A., Kapelner, A., Bleich, J., Pitkin, E., 2015. Peeking Inside the Black Box: Visualizing Statistical Learning With Plots of Individual Conditional Expectation. Journal of Computational and Graphical Statistics 24, 44-65. https://doi.org/10.1080/10618600.2014.907095

Goldthwait, S.A., Steinberg, D.K., 2008. Elevated biomass of mesozooplankton and enhanced fecal pellet flux in cyclonic and mode-water eddies in the Sargasso Sea. Deep Sea Research Part II: Topical Studies in Oceanography 55, 1360-1377. https://doi.org/10.1016/j.dsr2.2008.01.003

Gostiaux, L., van Haren, H., 2010. Extracting Meaningful Information from Uncalibrated Backscattered Echo Intensity Data. Journal of Atmospheric and Oceanic Technology 27, 943-949. https://doi.org/10.1175/2009JTECHO704.1

Grandperrin, R., 1975. Structures trophiques aboutissant aux thons de longue ligne dans le Pacifique sud-ouest tropical (PhD). Aix Marseille Universite.

Grandperrin, R., Auzende, J.M., Lafoy, Y., Lafoy, Y., Richer de Forges, B., Seret, B., Van Beuque, S., Virly, S., 1999. Swath-mapping and related deep-sea trawling in the southeastern part of the economic zone of New Caledonia. Presented at the Proceedings of the 5th Indo-Pacific Fish Conference, Noumea, New Caledonia, pp. 459-468.

Griffiths, F.B., Wadley, V.A., 1986. A synoptic comparison of fishes and crustaceans from a warm-core eddy, the East Australian Current, the Coral Sea and the Tasman Sea. Deep Sea Research Part A. Oceanographic Research Papers 33, 1907-1922.

Griffiths, G., 1996. Comparison of acoustic backscatter measurements from a ship-mounted Acoustic Doppler Current Profiler and an EK500 scientific echo-sounder. ICES Journal of Marine Science 53, 487-491. https://doi.org/10.1006/jmsc.1996.0070

Guinehut, S., Dhomps, A.-L., Larnicol, G., Le Traon, P.-Y., 2012. High Resolution 3-D temperature and salinity fields derived from in situ and satellite observations. Ocean Science Discussions 9, 1313-1347. https://doi.org/10.5194/osd-9-1313-2012

Guinehut, S., Le Traon, P.Y., Larnicol, G., Philipps, S., 2004. Combining Argo and remotesensing data to estimate the ocean three-dimensional temperature fields-a first approach based on simulated observations. Journal of Marine Systems 46, 85-98. https://doi.org/10.1016/j.jmarsys.2003.11.022

Handegard, N.O., Buisson, L. du, Brehmer, P., Chalmers, S.J., De Robertis, A., Huse, G., Kloser, R., Macaulay, G., Maury, O., Ressler, P.H., Stenseth, N.C., Godø, O.R., 2013. Towards an acoustic-based coupled observation and modelling system for monitoring and predicting ecosystem dynamics of the open ocean. Fish and Fisheries 14, 605615. https://doi.org/10.1111/j.1467-2979.2012.00480.x 
1092

1093

1094

1095

1096

1097

1098

1099

1100

1101

1102

1103

1104

1105

1106

1107

1108

1109

1110

1111

1112

1113

1114

1115

1116

1117

1118

1119

1120

1121

1122

1123

1124

1125

1126

1127

1128

1129

1130

1131

1132

1133

1134

1135

1136

1137

1138

1139

1140

Hastie, T., Tibshirani, R., 1995. Generalized Additive Models. Encyclopedia of Statistical Sciences.

Hauss, H., Christiansen, S., Schütte, F., Kiko, R., Edvam Lima, M., Rodrigues, E., Karstensen, J., Löscher, C.R., Körtzinger, A., Fiedler, B., 2016. Dead zone or oasis in the open ocean? Zooplankton distribution and migration in low-oxygen modewater eddies. Biogeosciences 13, 1977-1989. https://doi.org/10.5194/bg-13-1977-2016

Hays, G.C., 2003. A review of the adaptive significance and ecosystem consequences of zooplankton diel vertical migrations, in: Migrations and Dispersal of Marine Organisms. Springer, pp. 163-170.

Hazen, E., Friedlaender, A., Thompson, M., Ware, C., Weinrich, M., Halpin, P., Wiley, D., 2009. Fine-scale prey aggregations and foraging ecology of humpback whales Megaptera novaeangliae. Marine Ecology Progress Series 395, 75-89. https://doi.org/10.3354/meps08108

Hazen, E.L., Johnston, D.W., 2010. Meridional patterns in the deep scattering layers and top predator distribution in the central equatorial Pacific: Deep scattering layers in the central equatorial Pacific. Fisheries Oceanography 19, 427-433. https://doi.org/10.1111/j.1365-2419.2010.00561.x

Hegel, T.M., Cushman, S.A., Evans, J., Huettmann, F., 2010. Current State of the Art for Statistical Modelling of Species Distributions, in: Cushman, S.A., Huettmann, F. (Eds.), Spatial Complexity, Informatics, and Wildlife Conservation. Springer Japan, Tokyo, pp. 273-311. https://doi.org/10.1007/978-4-431-87771-4_16

Heino, M., Porteiro, F.M., Sutton, T.T., Falkenhaug, T., Godø, O.R., Piatkowski, U., 2011. Catchability of pelagic trawls for sampling deep-living nekton in the mid-North Atlantic. ICES Journal of Marine Science 68, 377-389. https://doi.org/0.1093/icesjms/fsq089

Hewitt, R.P., Demer, D.A., Emery, J.H., 2003. An 8-year cycle in krill biomass density inferred from acoustic surveys conducted in the vicinity of the South Shetland Islands during the austral summers of 1991-1992 through 2001-2002. Aquatic Living Resources 9.

Hummon, J.M., Firing, E., 2003. A Direct Comparison of Two RDI Shipboard ADCPs: A 75$\mathrm{kHz}$ Ocean Surveyor and a $150-\mathrm{kHz}$ Narrow Band*. Journal of Atmospheric and Oceanic Technology 20, 872-888.

Irigoien, X., Klevjer, T.A., Røstad, A., Martinez, U., Boyra, G., Acuña, J.L., Bode, A., Echevarria, F., Gonzalez-Gordillo, J.I., Hernandez-Leon, S., Agusti, S., Aksnes, D.L., Duarte, C.M., Kaartvedt, S., 2014. Large mesopelagic fishes biomass and trophic efficiency in the open ocean. Nature Communications 5. https://doi.org/10.1038/ncomms4271

Kaartvedt, S., Staby, A., Aksnes, D., 2012. Efficient trawl avoidance by mesopelagic fishes causes large underestimation of their biomass. Marine Ecology Progress Series 456, 1-6. https://doi.org/10.3354/meps09785

Kaneda, A. et al, Takeoka, H., Koizumi, Y., 2002. Periodic Occurrence of Diurnal Signal of ADCP Backscatter Strength in Uchiumi Bay, Japan. Estuarine, Coastal and Shelf Science 55, 323-330.

Kessler, W.S., Cravatte, S., 2013. Mean circulation of the Coral Sea. Journal of Geophysical Research: Oceans 118, 6385-6410. https://doi.org/10.1002/2013JC009117

Kiko, R., Biastoch, A., Brandt, P., Cravatte, S., Hauss, H., Hummels, R., Kriest, I., Marin, F., McDonnell, A.M.P., Oschlies, A., Picheral, M., Schwarzkopf, F.U., Thurnherr, A.M., Stemmann, L., 2017. Biological and physical influences on marine snowfall at the equator. Nature Geoscience 10, 852-858. https://doi.org/10.1038/ngeo3042 
1168

1169

1170

1171

1172

1173

1174

1175

1176

1177

1178

1179

1180

1181

1182

1183

1184

1185

1186

1187

1188

Klevjer, T.A., Irigoien, X., Røstad, A., Fraile-Nuez, E., Benítez-Barrios, V.M., Kaartvedt., S., 2016. Large scale patterns in vertical distribution and behaviour of mesopelagic scattering layers. Scientific Reports 6, 19873. https://doi.org/10.1038/srep19873

Kloser, R.J., Ryan, T., Sakov, P., Williams, A., Koslow, J.A., 2002. Species identification in deep water using multiple acoustic frequencies. Canadian Journal of Fisheries and Aquatic Sciences 59, 1065-1077. https://doi.org/10.1139/f02-076

Kloser, R.J., Ryan, T.E., Keith, G., Gershwin, L., 2016. Deep-scattering layer, gas-bladder density, and size estimates using a two-frequency acoustic and optical probe. ICES Journal of Marine Science: Journal du Conseil 73, 2037-2048. https://doi.org/10.1093/icesjms/fsv257

Kloser, R.J., Ryan, T.E., Young, J.W., Lewis, M.E., 2009. Acoustic observations of micronekton fish on the scale of an ocean basin: potential and challenges. ICES Journal of Marine Science: Journal du Conseil fsp077.

Koubbi, P., Moteki, M., Duhamel, G., Goarant, A., Hulley, P.-A., O’Driscoll, R., Ishimaru, T., Pruvost, P., Tavernier, E., Hosie, G., 2011. Ecoregionalization of myctophid fish in the Indian sector of the Southern Ocean: Results from generalized dissimilarity models. Deep Sea Research Part II: Topical Studies in Oceanography 58, 170-180. https://doi.org/10.1016/j.dsr2.2010.09.007

Lavery, A.C., Wiebe, P.H., Stanton, T.K., Lawson, G.L., Benfield, M.C., Copley, N., 2007. Determining dominant scatterers of sound in mixed zooplankton populations. The Journal of the Acoustical Society of America 122, 3304. https://doi.org/10.1121/1.2793613

Lebourges-Dhaussy, A., Huggett, J., Ockhuis, S., Roudaut, G., Josse, E., Verheye, H., 2014. Zooplankton size and distribution within mesoscale structures in the Mozambique Channel: A comparative approach using the TAPS acoustic profiler, a multiple net sampler and ZooScan image analysis. Deep Sea Research Part II: Topical Studies in Oceanography 100, 136-152. https://doi.org/10.1016/j.dsr2.2013.10.022

Lee, K., Mukai, T., Kamg, D., Iida, K., 2004. Application of acoustic Doppler current profiler combined with a scientific echo sounder for krill Euphausia pacifica density estimation. Fisheries science 70, 1051-1060.

Lehodey, P., Conchon, A., Senina, I., Domokos, R., Calmettes, B., Jouanno, J., Hernandez, O., Kloser, R., 2015. Optimization of a micronekton model with acoustic data. ICES Journal of Marine Science 72, 1399-1412. https://doi.org/10.1093/icesjms/fsu233

Lehodey, P., Murtugudde, R., Senina, I., 2010. Bridging the gap from ocean models to population dynamics of large marine predators: A model of mid-trophic functional groups. Progress in Oceanography 84, 69-84. https://doi.org/10.1016/j.pocean.2009.09.008

Lehodey, P., Senina, I., Murtugudde, R., 2008. A spatial ecosystem and populations dynamics model (SEAPODYM) - Modeling of tuna and tuna-like populations. Progress in Oceanography 78, 304-318.

Liljebladh, B., Thomasson, M.A., 2001. Krill behaviour as recorded by acoustic doppler current profilers in the Gullmarsfjord. Journal of Marine Systems 27, 301-313.

Maas, A.E., Frazar, S.L., Outram, D.M., Seibel, B.A., Wishner, K.F., 2014. Fine-scale vertical distribution of macroplankton and micronekton in the Eastern Tropical North Pacific in association with an oxygen minimum zone. Journal of Plankton Research 36, 15571575. https://doi.org/10.1093/plankt/fbu077

Mantua, N.J., Hare, S.R., 2002. The Pacific Decadal Oscillation. journal of oceanography 58, 35-44. 
Marchesiello, P., Lefèvre, J., Vega, A., Couvelard, X., Menkes, C., 2010. Coastal upwelling, circulation and heat balance around New Caledonia's barrier reef. Marine Pollution Bulletin 61, 432-448. https://doi.org/10.1016/j.marpolbul.2010.06.043

McGillicuddy, D.J., Anderson, L.A., Bates, N.R., Bibby, T., Buesseler, K.O., Carlson, C.A., Davis, C.S., Ewart, C., Falkowski, P.G., Goldthwait, S.A., Hansell, D.A., Jenkins, W.J., Johnson, R., Kosnyrev, V.K., Ledwell, J.R., Li, Q.P., Siegel, D.A., Steinberg, D.K., 2007. Eddy/Wind Interactions Stimulate Extraordinary Mid-Ocean Plankton Blooms. Science 316, 1021-1026. https://doi.org/10.1126/science.1136256

Ménard, F., Marchal, E., 2003. Foraging behaviour of tuna feeding on small schooling Vinciguerria nimbaria in the surface layer of the equatorial Atlantic Ocean. Aquatic Living Resources 16, 231-238. https://doi.org/10.1016/S0990-7440(03)00040-8

Menkes, C.E., Allain, V., Rodier, M., Gallois, F., Lebourges-Dhaussy, A., Hunt, B.P.V., Smeti, H., Pagano, M., Josse, E., Daroux, A., Lehodey, P., Senina, I., Kestenare, E., Lorrain, A., Nicol, S., 2015. Seasonal oceanography from physics to micronekton in the south-west Pacific. Deep Sea Research Part II: Topical Studies in Oceanography 113, 125-144. https://doi.org/10.1016/j.dsr2.2014.10.026

Meyer, D., Dimitriadou, E., Hornik, K., Weingessel, A., Leisch, F., 2017. e1071: Misc Functions of the Department of Statistics, Probability Theory Group (Formerly: E1071), TU Wien.

Michalsky, J.J., 1988. The Astronomical Almanac's algorithm for approximate solar position (1950-2050). Solar Energy 40, 227-235. https://doi.org/10.1016/0038092X(88)90045-X

Miller, D.L., Burt, M.L., Rexstad, E.A., Thomas, L., 2013. Spatial models for distance sampling data: recent developments and future directions. Methods in Ecology and Evolution 4, 1001-1010. https://doi.org/10.1111/2041-210X.12105

Morato, T., Hoyle, S.D., Allain, V., Nicol, S.J., 2010. Seamounts are hotspots of pelagic biodiversity in the open ocean. Proceedings of the National Academy of Sciences 107, 9707-9711.

Morato, T., Varkey, D., Damaso, C., Machete, M., Santos, M., Prieto, R., Pitcher, T., Santos, R., 2008. Evidence of a seamount effect on aggregating visitors. Marine Ecology Progress Series 357, 23-32. https://doi.org/10.3354/meps07269

Mulet, S., Rio, M.-H., Mignot, A., Guinehut, S., Morrow, R., 2012. A new estimate of the global 3D geostrophic ocean circulation based on satellite data and in-situ measurements. Deep Sea Research Part II: Topical Studies in Oceanography 77-80, 70-81. https://doi.org/10.1016/j.dsr2.2012.04.012

Muller, K.-R., Mika, S., Ratsch, G., Tsuda, K., Scholkopf, B., 2001. An introduction to kernel-based learning algorithms. IEEE Transactions on Neural Networks 12, 181201. https://doi.org/10.1109/72.914517

Muller-Karger, F.E., Miloslavich, P., Bax, N.J., Simmons, S., Costello, M.J., Sousa Pinto, I., Canonico, G., Turner, W., Gill, M., Montes, E., Best, B.D., Pearlman, J., Halpin, P., Dunn, D., Benson, A., Martin, C.S., Weatherdon, L.V., Appeltans, W., Provoost, P., Klein, E., Kelble, C.R., Miller, R.J., Chavez, F.P., Iken, K., Chiba, S., Obura, D., Navarro, L.M., Pereira, H.M., Allain, V., Batten, S., Benedetti-Checchi, L., Duffy, J.E., Kudela, R.M., Rebelo, L.-M., Shin, Y., Geller, G., 2018. Advancing Marine Biological Observations and Data Requirements of the Complementary Essential Ocean Variables (EOVs) and Essential Biodiversity Variables (EBVs) Frameworks. Front. Mar. Sci. 5. https://doi.org/10.3389/fmars.2018.00211

Nishikawa, J., Nishida, S., Moku, M., Hidaka, K., Kawaguchi, K., 2001. Biomass, Abundance, and Vertical Distribution of Micronekton and Large Gelatinous 
Zooplankton in the Subarctic Pacific and the Bering Sea during the Summer of 1997. Journal of Oceanography 57, 361-375. https://doi.org/10.1023/A:1012494931701

O'Brien, R.M., 2007. A Caution Regarding Rules of Thumb for Variance Inflation Factors. Quality \& Quantity 41, 673-690. https://doi.org/10.1007/s11135-006-9018-6

Olson, R., Duffy, L., Kuhnert, P., Galván-Magaña, F., Bocanegra-Castillo, N., AlatorreRamírez, V., 2014. Decadal diet shift in yellowfin tuna Thunnus albacares suggests broad-scale food web changes in the eastern tropical Pacific Ocean. Marine Ecology Progress Series 497, 157-178. https://doi.org/10.3354/meps10609

Oppel, S., Meirinho, A., Ramírez, I., Gardner, B., O’Connell, A.F., Miller, P.I., Louzao, M., 2012. Comparison of five modelling techniques to predict the spatial distribution and abundance of seabirds. Biological Conservation 156, 94-104. https://doi.org/10.1016/j.biocon.2011.11.013

Palialexis, A., Georgakarakos, S., Karakassis, I., Lika, K., Valavanis, V.D., 2011. Prediction of marine species distribution from presence-absence acoustic data: comparing the fitting efficiency and the predictive capacity of conventional and novel distribution models. Hydrobiologia 670, 241-266. https://doi.org/10.1007/s10750-011-0673-9

Payri, C., 2018. Nouvelle-Calédonie, Archipel de corail, 1ère édition. ed, hors collection. IRD Editions/Solaris.

Pearre, S., 2003. Eat and run? The hunger/satiation hypothesis in vertical migration: history, evidence and consequences. Biological Reviews of the Cambridge Philosophical Society 78, 1-79. https://doi.org/10.1017/S146479310200595X

Potier, M., Bach, P., Ménard, F., Marsac, F., 2014. Influence of mesoscale features on micronekton and large pelagic fish communities in the Mozambique Channel. Deep Sea Research Part II: Topical Studies in Oceanography 100, 184-199. https://doi.org/10.1016/j.dsr2.2013.10.026

Proud, R., Handegard, N.O., Kloser, R.J., Cox, M.J., Brierley, A.S., Handling editor: David Demer, 2018. From siphonophores to deep scattering layers: uncertainty ranges for the estimation of global mesopelagic fish biomass. ICES Journal of Marine Science. https://doi.org/10.1093/icesjms/fsy037

Pujol, M.-I., Faugere, Y., Taburet, G., Dupuy, S., Pelloquin, C., Ablain, M., Picot, N., 2016. DUACS DT2014: the new multi-mission altimeter data set reprocessed over 20 years. Ocean Science 12, 1067-1090. https://doi.org/10.5194/os-12-1067-2016

Qiu, B., Chen, S., Kessler, W.S., 2009. Source of the 70-Day Mesoscale Eddy Variability in the Coral Sea and the North Fiji Basin*. Journal of Physical Oceanography 39, 404420. https://doi.org/10.1175/2008JPO3988.1

Quetin, L.B., Ross, R.M., 2003. Episodic recruitment in Antarctic krill Euphausia superba in the Palmer LTER study region. Marine Ecology Progress Series 25, 185-200.

Radenac, M.-H., Léger, F., Singh, A., Delcroix, T., 2012. Sea surface chlorophyll signature in the tropical Pacific during eastern and central Pacific ENSO events. Journal of Geophysical Research: Oceans 117. https://doi.org/10.1029/2011JC007841

Radenac, M.-H., Plimpton, P.E., Lebourges-Dhaussy, A., Commien, L., McPhaden, M.J., 2010. Impact of environmental forcing on the acoustic backscattering strength in the equatorial Pacific: Diurnal, lunar, intraseasonal, and interannual variability. Deep Sea Research Part I: Oceanographic Research Papers 57, 1314-1328. https://doi.org/10.1016/j.dsr.2010.06.004

RDI, I., 1998. Calculating Absolute Backscatter in Narrowband ADCPs.

Reynolds, R.W., Smith, T.M., Liu, C., Chelton, D.B., Casey, K.S., Schlax, M.G., 2007. Daily High-Resolution-Blended Analyses for Sea Surface Temperature. Journal of Climate 20, 5473-5496. https://doi.org/10.1175/2007JCLI1824.1 
Rousselet, L., Doglioli, A.M., Maes, C., Blanke, B., Petrenko, A.A., 2016. Impacts of mesoscale activity on the water masses and circulation in the Coral Sea. Journal of Geophysical Research: Oceans 121.

Sabarros, P., Ménard, F., Lévénez, J., Tew-Kai, E., Ternon, J., 2009. Mesoscale eddies influence distribution and aggregation patterns of micronekton in the Mozambique Channel. Marine Ecology Progress Series 395, 101-107. https://doi.org/10.3354/meps08087

Saulquin, B., Gohin, F., Garello, R., 2009. Regional objective analysis for merging MERIS, MODIS/Aqua and SeaWiFS Chlorophyll-a data from 1998 to 2008 on the European Atlantic Shelf at a resolution of $1.1 \mathrm{Km}$. Oceans 2009 - Europe 1, 1165-1174. https://doi.org/10.1109/OCEANSE.2009.5278165

Scoulding, B., Chu, D., Ona, E., Fernandes, P.G., 2015. Target strengths of two abundant mesopelagic fish species. The Journal of the Acoustical Society of America 137, 9891000.

Smeti, H., Pagano, M., Menkes, C., Lebourges-Dhaussy, A., Hunt, B.P.V., Allain, V., Rodier, M., de Boissieu, F., Kestenare, E., Sammari, C., 2015. Spatial and temporal variability of zooplankton off New Caledonia (Southwestern Pacific) from acoustics and net measurements. Journal of Geophysical Research: Oceans 120, 2676-2700. https://doi.org/10.1002/2014JC010441

Sutton, T.T., Clark, M.R., Dunn, D.C., Halpin, P.N., Rogers, A.D., Guinotte, J., Bograd, S.J., Angel, M.V., Perez, J.A.A., Wishner, K., Haedrich, R.L., Lindsay, D.J., Drazen, J.C., Vereshchaka, A., Piatkowski, U., Morato, T., Błachowiak-Samołyk, K., Robison, B.H., Gjerde, K.M., Pierrot-Bults, A., Bernal, P., Reygondeau, G., Heino, M., 2017. A global biogeographic classification of the mesopelagic zone. Deep Sea Research Part I: Oceanographic Research Papers 126, 85-102. https://doi.org/10.1016/j.dsr.2017.05.006

Tarling, G.A., Matthews, J.B.L., David, P., Guerin, O., Buchholz, F., 2001. The swarm dynamics of northern krill (Meganyctiphanes norvegica) and pteropods (Cavolinia inyexa) during vertical migration in the Ligurian Sea observed by an acoustic Doppler current pro"ler 16.

Tew Kai, E., Marsac, F., 2010. Influence of mesoscale eddies on spatial structuring of top predators' communities in the Mozambique Channel. Progress in Oceanography 86, 214-223. https://doi.org/10.1016/j.pocean.2010.04.010

Vourey, E., Dupouy, C., Harold, A. scott, 2017. A new species of Polyipnus (Stomiiformes: Sternoptychidae) from the Western South Pacific. Zootaxa 4263, 567-577.

Wentz, F.J., Scott, R.H., Leidner, M., Atlas, R., Ardizzone, J., 2015. Remote Sensing Systems Cross-Calibrated Multi-Platform (CCMP) 6-hourly ocean vector wind analysis product on 0.25 deg grid, Remote Sensing Systems. Santa Rosa, CA.

Williams, A.J., Allain, V., Nicol, S.J., Evans, K.J., Hoyle, S.D., Dupoux, C., Vourey, E., Dubosc, J., 2014. Vertical behavior and diet of albacore tuna (Thunnus alalunga) vary with latitude in the South Pacific Ocean. Deep Sea Research Part II.

Wood, S., 2006. Generalized additive models: an introduction with R. CRC press.

Wood, S.N., 2017. Generalized Additive Models: An Introduction with R, Second Edition, Chapman \& Hall/CRC Texts in Statistical Science.

Wood, S.N., 2011. Fast stable restricted maximum likelihood and marginal likelihood estimation of semiparametric generalized linear models: Estimation of Semiparametric Generalized Linear Models. Journal of the Royal Statistical Society: Series B (Statistical Methodology) 73, 3-36. https://doi.org/10.1111/j.1467-9868.2010.00749.x 
1335 Wood, S.N., Scheipl, F., Faraway, J.J., 2012. Straightforward intermediate rank tensor product smoothing in mixed models. Statistics and Computing 23, 341-360. https://doi.org/10.1007/s11222-012-9314-z

Young, J.W., Hobday, A.J., Campbell, R.A., Kloser, R.J., Bonham, P.I., Clementson, L.A., Lansdell, M.J., 2011. The biological oceanography of the East Australian Current and surrounding waters in relation to tuna and billfish catches off eastern Australia. Deep Sea Research Part II: Topical Studies in Oceanography 58, 720-733. https://doi.org/10.1016/j.dsr2.2010.10.005

Young, J.W., Hunt, B.P.V., Cook, T.R., Llopiz, J.K., Hazen, E.L., Pethybridge, H.R., Ceccarelli, D., Lorrain, A., Olson, R.J., Allain, V., Menkes, C., Patterson, T., Nicol, S., Lehodey, P., Kloser, R.J., Arrizabalaga, H., Anela Choy, C., 2015. The trophodynamics of marine top predators: Current knowledge, recent advances and challenges. Deep Sea Research Part II: Topical Studies in Oceanography 113, 170 187. https://doi.org/10.1016/j.dsr2.2014.05.015

Young, J.W., Lansdell, M.J., Campbell, R.A., Cooper, S.P., Juanes, F., Guest, M.A., 2010. Feeding ecology and niche segregation in oceanic top predators off eastern Australia. Marine Biology 157, 2347-2368. https://doi.org/10.1007/s00227-010-1500-y

ZoNéCo, 2013. L’atlas bathymétrique de la Nouvelle-Calédonie. ZoNéCo. 

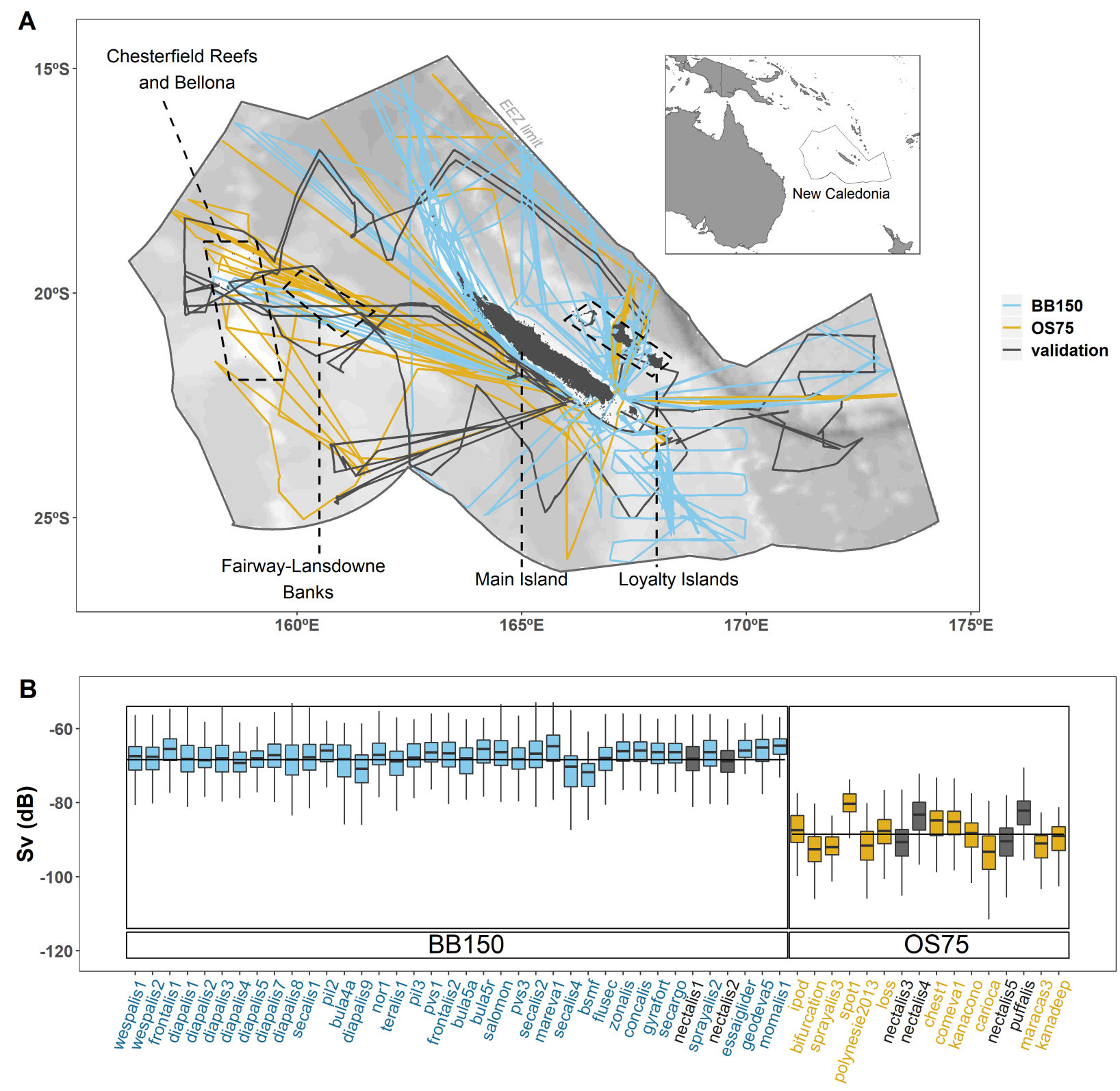


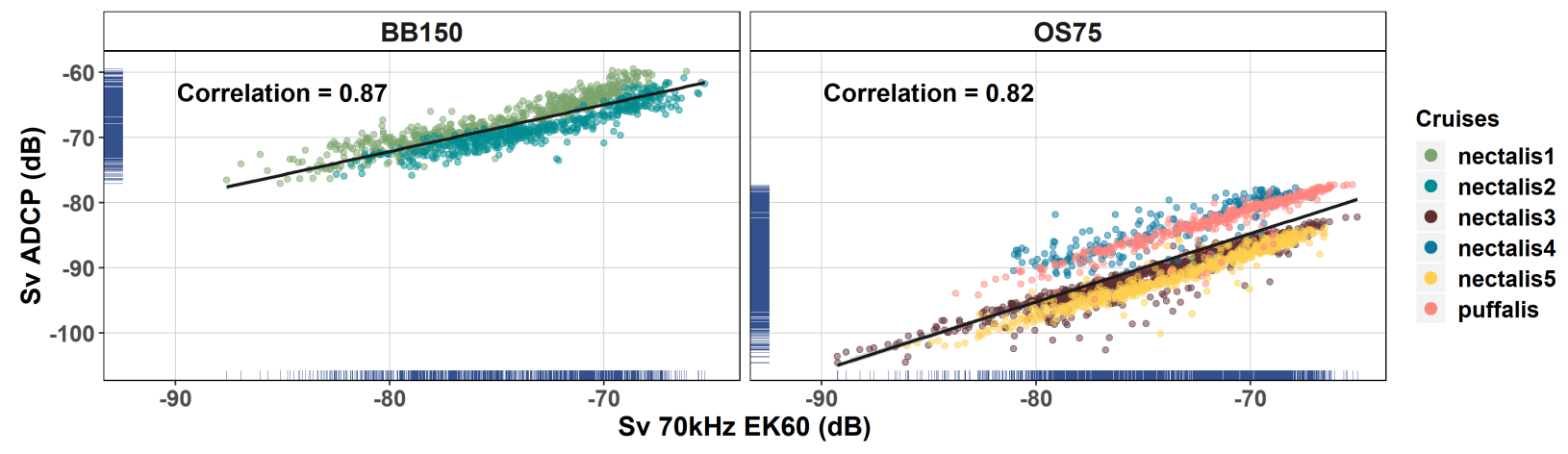




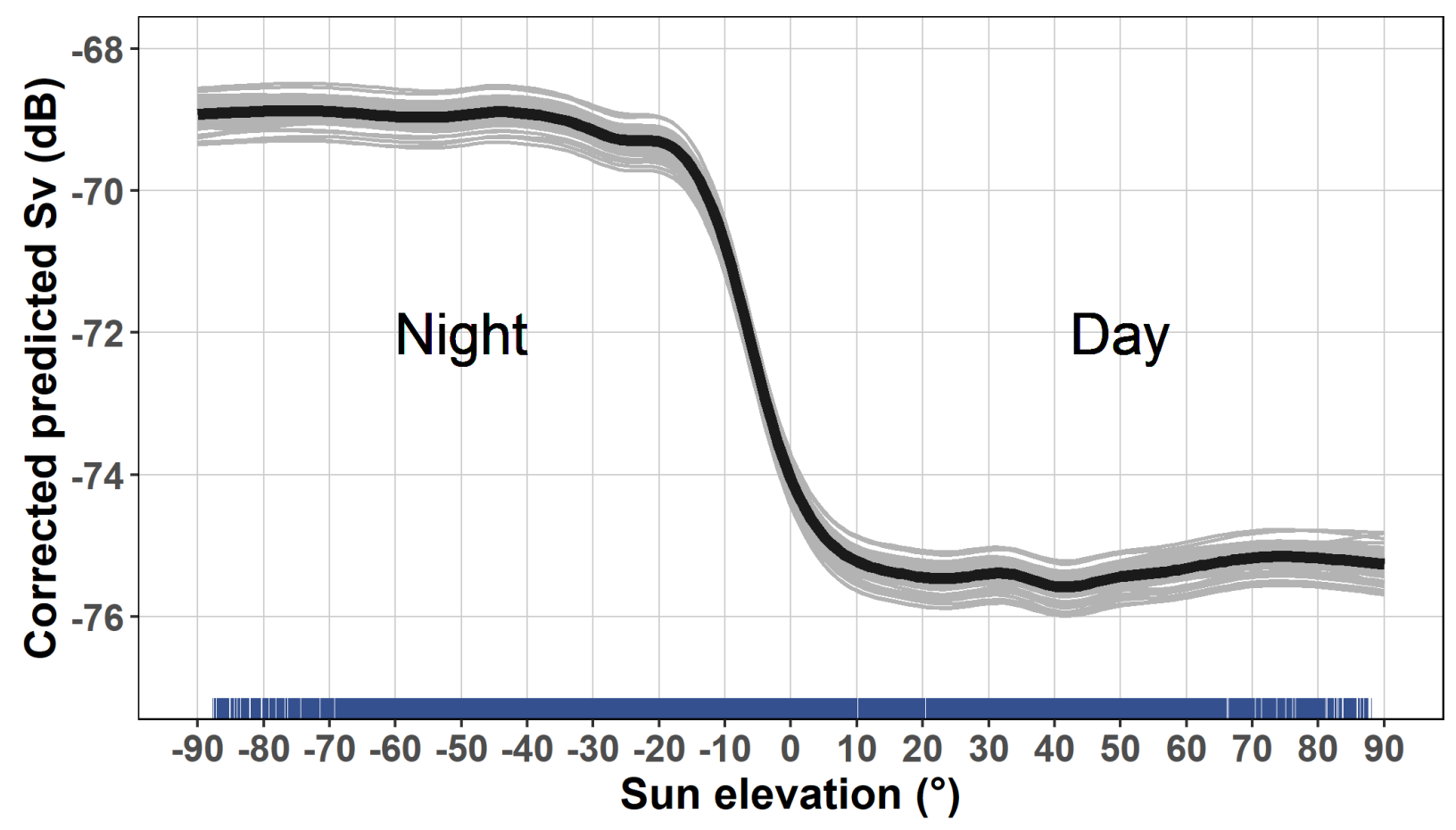




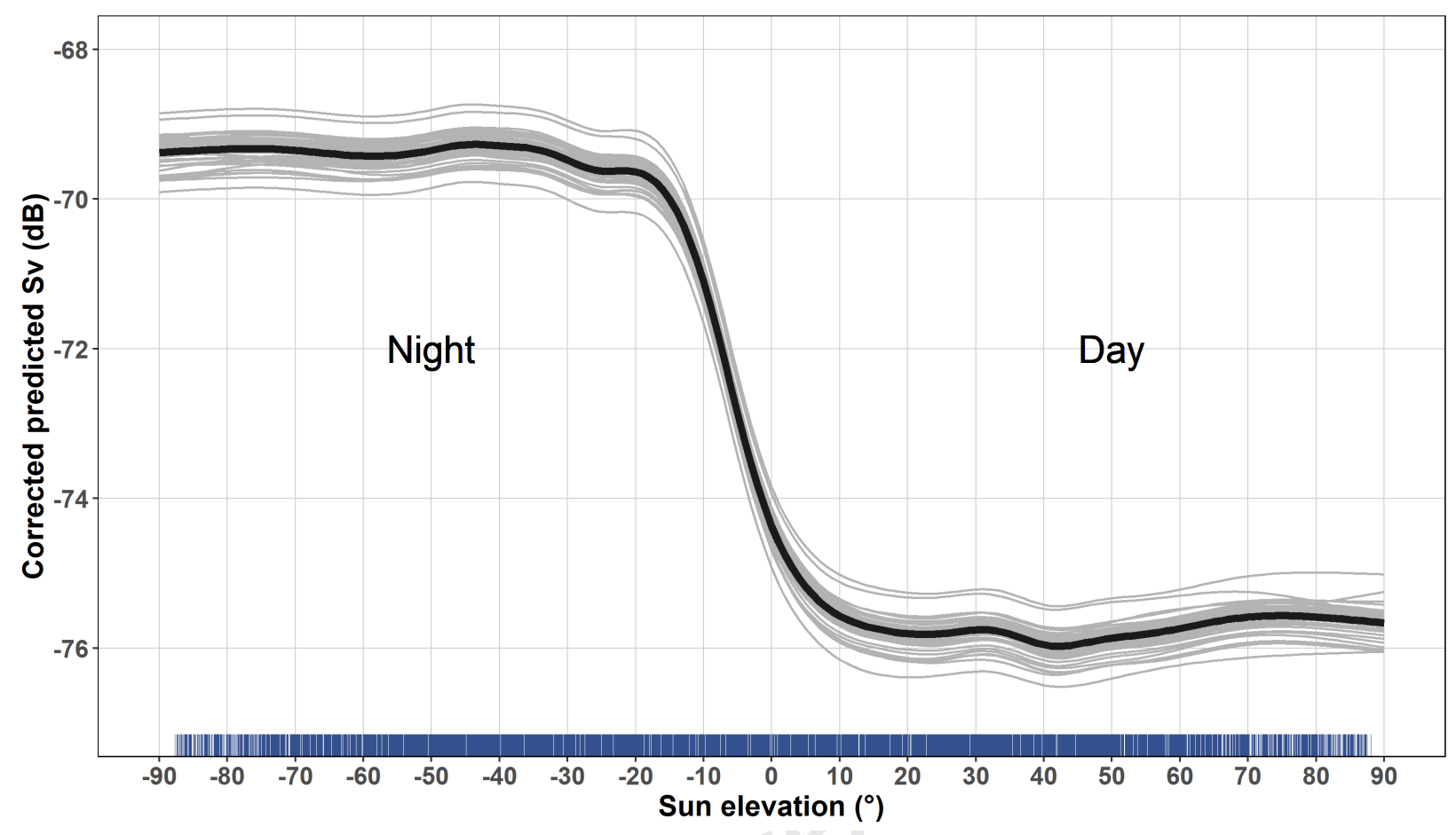




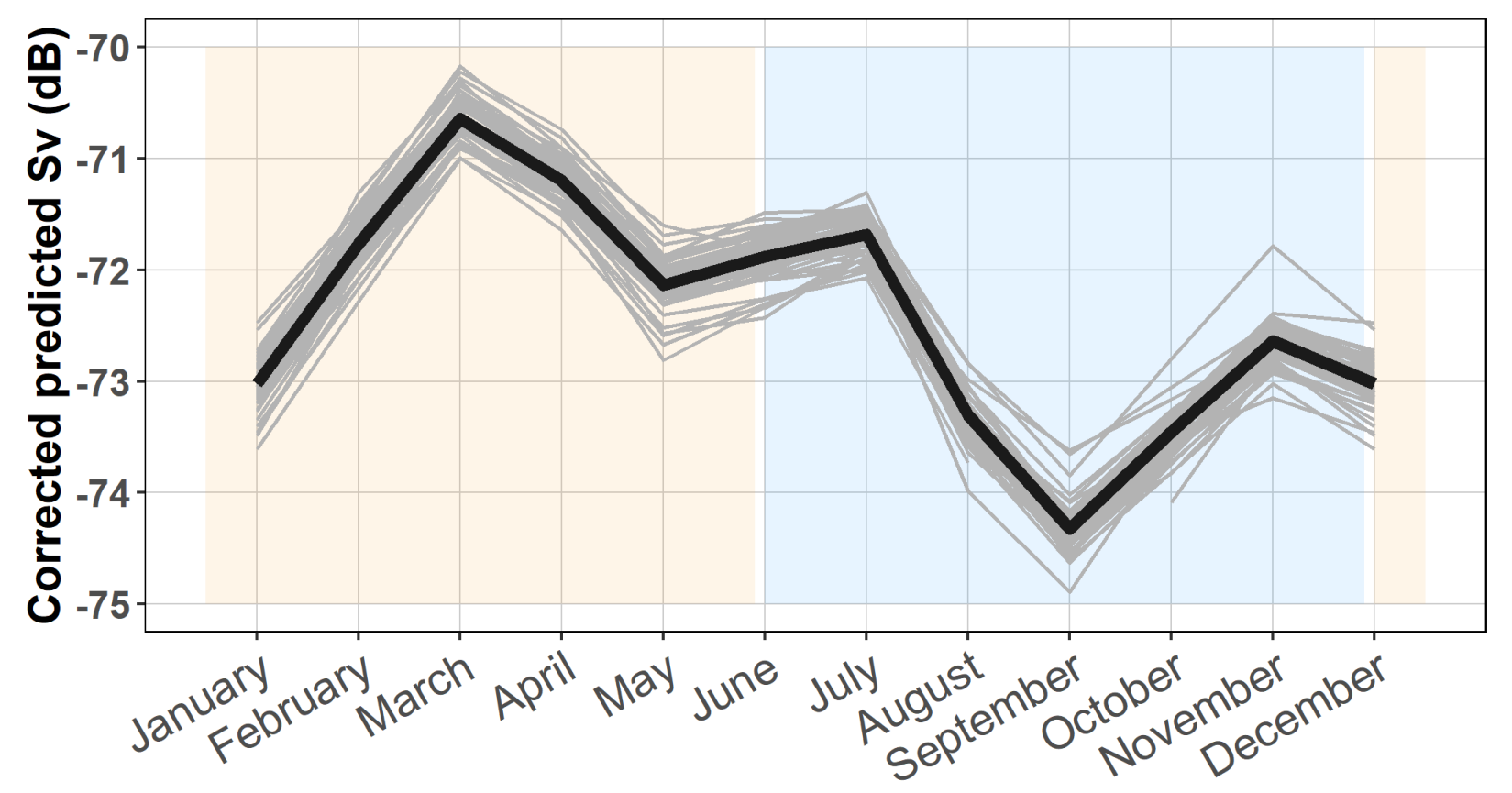



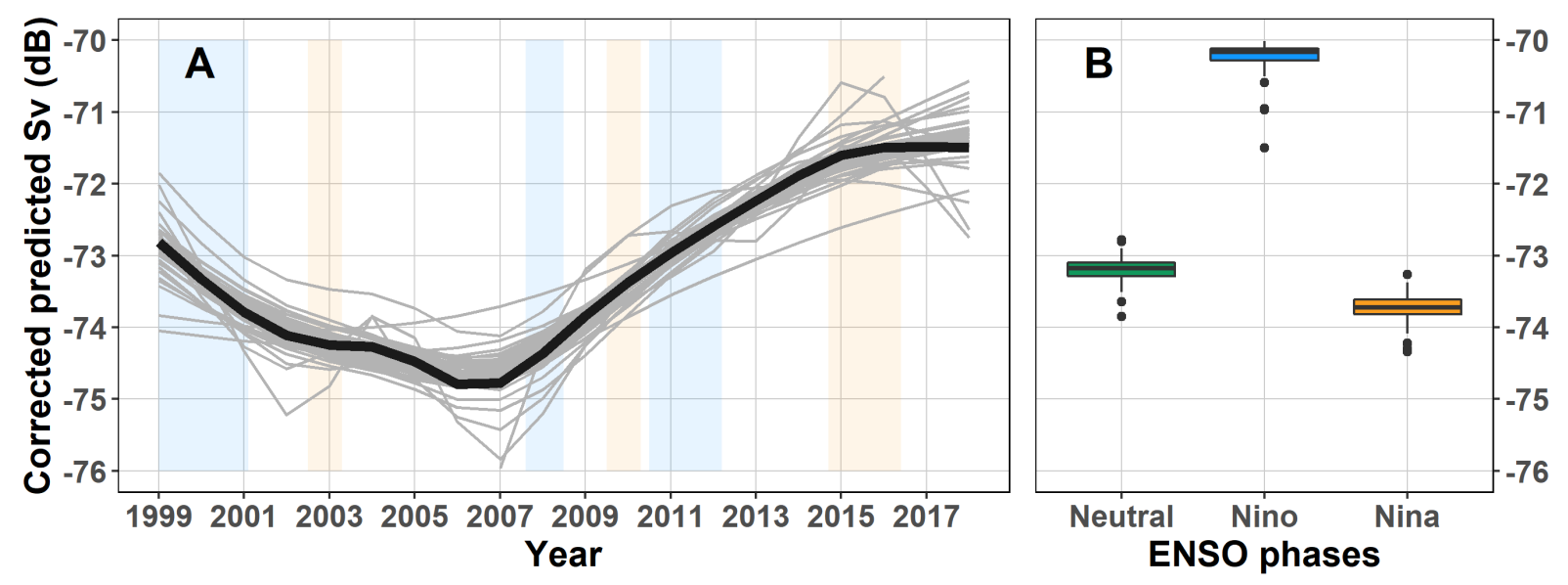

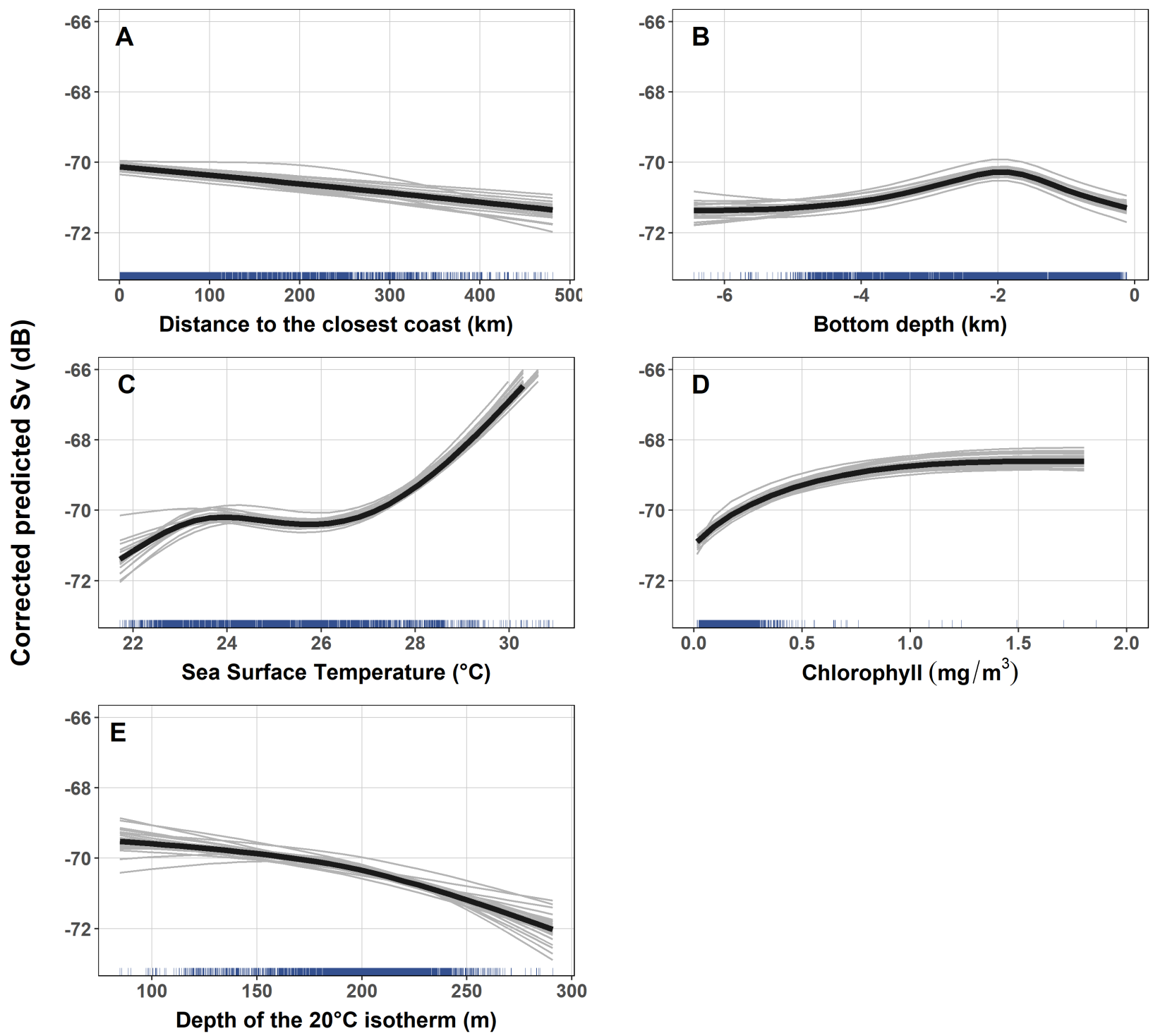
A
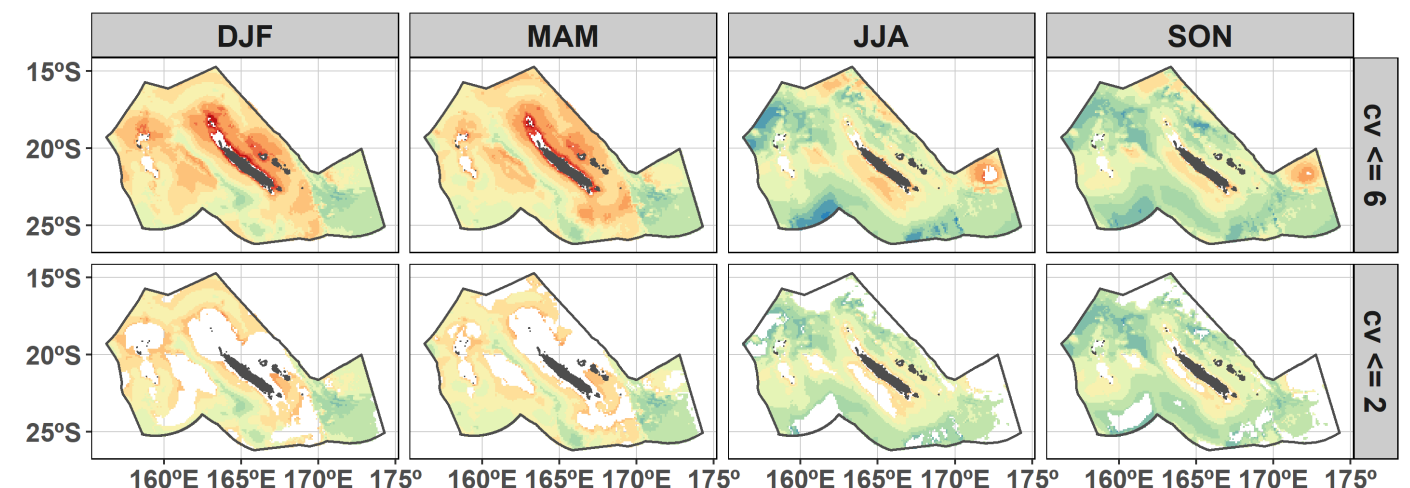

$160^{\circ} \mathrm{E} 165^{\circ} \mathrm{E} 170^{\circ} \mathrm{E} \quad 175^{\circ} \quad 160^{\circ} \mathrm{E} 165^{\circ} \mathrm{E} 170^{\circ} \mathrm{E} 175^{\circ}$

$160^{\circ} \mathrm{E} 165^{\circ} \mathrm{E} 170^{\circ} \mathrm{E} 175^{\circ}$

Mean corrected predicted

B

Sv by GAMM and SVM (dB)

$\begin{array}{llllllllllllll}-100 & -73 & -72.5 & -72 & -71.5 & -71 & -70.5 & -70 & -69.5 & -69 & -68.5 & -68 & -67.5 & -67\end{array}$
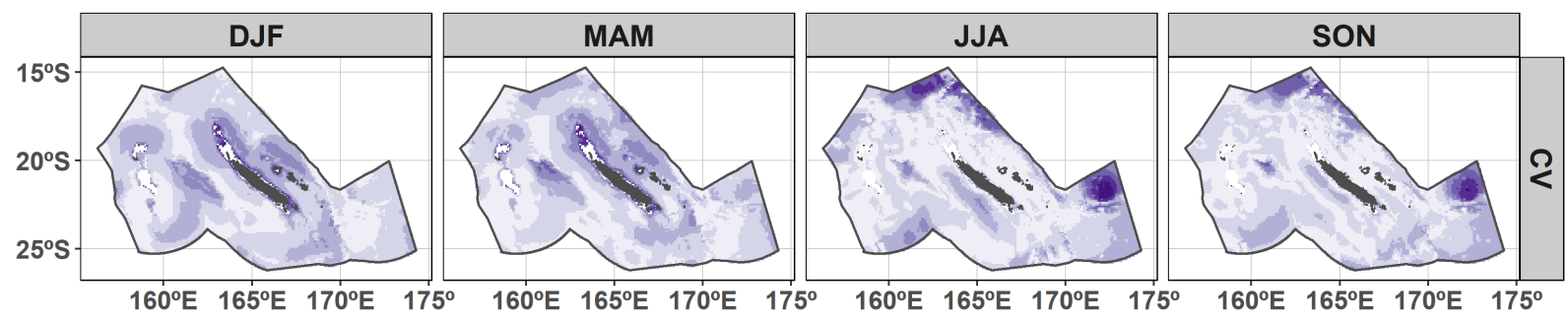

Variation coefficient (\%)

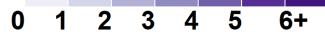



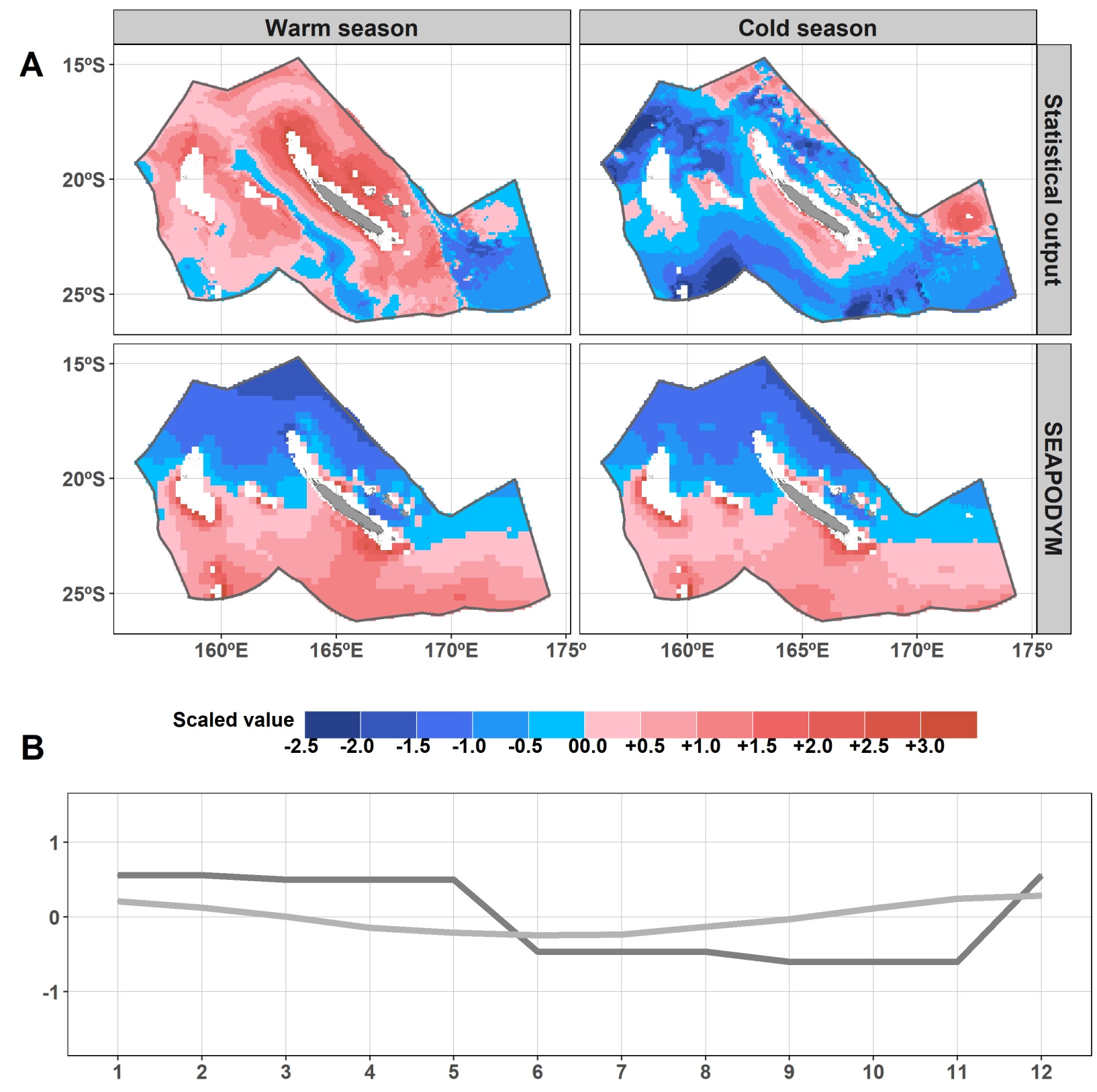

Scaled value $\square$ Statistical output $\square$ SEAPODYM 


\section{Highlights}

- 20 years of ADCP acoustic data give insights on spatiotemporal micronekton dynamics

- Sea-surface temperature is the main factor driving the backscatter variability

- Backscatter values are enhanced during El Niño events in New Caledonia's EEZ

- Micronekton spatial distribution changes across seasons according to backscatter

- Spatial and temporal distribution of micronekton differ between SEAPODYM and ADCP' 


\section{Declaration of interests}

$\bigotimes$ The authors declare that they have no known competing financial interests or personal relationships that could have appeared to influence the work reported in this paper.

$\square$ The authors declare the following financial interests/personal relationships which may be considered as potential competing interests: 